\title{
Can You Relate? The Importance of Need Satisfaction for the Quality and Progressive Union Formation Process of Intimate Relationships
}

\author{
Franziska Schmahl, Sabine Walper
}

\begin{abstract}
Summary: This article deals with the significance of autonomy and relatedness as central needs in intimate relationships. It examines the influences of need satisfaction on relationship quality and progressive union formation ("institutionalisation") processes of intimate relationships. Using a random sample of 1,914 couples in a longitudinal, dyadic survey design, we ascertained the actor and partner effects of autonomy and relatedness on relationship quality and the union formation process. A cluster analysis resulted in four types of relationship need satisfaction, distinguished by high values in both domains, high values in only one of the domains, or low need satisfaction in both domains. Balanced fulfilment of autonomy and relatedness predicts the comparatively highest values of relationship satisfaction and future orientation (commitment). Moreover, low need satisfaction in relationships reduces the progress of union formation processes (cohabitation, marriage, childbirth). Women demonstrate more intense actor and partner effects of relationship need satisfaction than men.
\end{abstract}

Keywords: Need satisfaction · Autonomy · Relatedness · Intimate relationships · Gender difference

\section{Introduction}

Successful intimate relationships make an important contribution to personal wellbeing (e.g. Braithwaite et al. 2010). Insecure or unsatisfactory relationships, by contrast, are identified in health surveys as one of the most significant influencing factors for the development of psychological disorders such as anxiety disorders or affective disorders (Whisman 2007). Many studies, however, do not reveal in what way an intimate relationship influences personal well-being (e.g. Berscheid/Regan 2005; Lucas/Dyrenforth 2006). The fulfilment of important psychological needs by an intimate relationship can be considered an obvious mechanism. In particular the 
fulfilment of the need for relatedness - demonstrated by sharing intimate thoughts and feelings and the experience of emotional closeness in the relationship with an appreciative partner (Patrick et al. 2007) - has been given great academic attention in the past (e.g. Baumeister/Leary 1995; La Guardia/Patrick 2008). The fact that the fulfilment of the need for autonomy also plays a role in intimate relationships has only been discussed more intensively in the past two decades - often with reference to the self-determination theory (SDT) of Ryan and Deci (2008). Personal need satisfaction in relationships also appears relevant in the course of the social change of values (Oesterdiekhoff/Jegelka 2001), which is characterised by an increasing importance of self-fulfilment values such as autonomy and self-actualisation. Hence, personal expectations for happiness become increasingly central of intimate relationships, while the obligating and binding character linked, for example, with marriage, is losing significance (Peuckert 2008).

In the following, we will first present relevant theoretical concepts and empirical findings that speak for a positive influence of autonomy and relatedness on the success of intimate relationships. Then, we will examine on a broad data basis what significance the fulfilment and balance of autonomy and relatedness in a relationship has for its development. In addition to exploring the effects of need satisfaction and balance on subjective dimensions of relationship quality, we will also for the first time investigate their effects on the union formation process via event data. In doing so, we employ a longitudinal dyadic research design, which enables us to model differential effects of need satisfaction for men and women and their reciprocal influences.

\section{Autonomy and relatedness in intimate relationships}

\subsection{Theoretical perspectives}

The idea that there are two fundamental themes in human life - the aspiration to realise one's own goals and the aspiration to find intimacy with important attachment figures - was taken up in the past by theoreticians of various academic schools (e.g. Angyal 1951; Bakan 1966; Franz/White 1985). In the traditional psychological needs theories of Murray (1938) or Maslow (1955) these aspirations were seen as basic human needs for relatedness or for autonomy and self-actualisation. Furthermore, such needs again received more attention in more recent psychological theories such as the self-determination theory (Ryan/Deci 2008). From the perspective of the self-determination theory, fulfilment of the needs for autonomy and relatedness is highly relevant not only in the context of parent-child or teacher-student relationships, but also with respect to the formation and perpetuation of intimate relationships (e.g. La Guardia/Patrick 2008; Patrick et al. 2007). In addition to the need for competence, the self-determination theory conceptualises autonomy and relatedness as basic psychological human needs, the fulfilment of which is "essential for ongoing psychological growth, integrity, and well-being" (Deci/Ryan 2000: 229). 
Unlike motives that can vary depending on one's personal experiences of socialisation, needs are understood as innate and universal aspirations of all humans and their fulfilment is always linked to well-being and personal growth (Ryan/Deci 2008). In the self-determination theory relatedness - or the need to belong - refers to the aspiration for strong and robust interpersonal bonds (Baumeister/Leary 1995; Ryan/ Deci 2000). In intimate relationships, it is exemplified through the perceived appreciation and care by the relationship partner or by perceived closeness and intimacy in the relationship. In the context of close relationships, autonomy is understood as the feeling of self-determination and the potential exercise of influence on the relationship (cf. "Basic Need Satisfaction in Relationships Scale", La Guardia et al. 2000). Autonomy therefore is not the same thing as independence or separateness; "autonomy does not entail being subject to no external influences" (Ryan 1993: 10). Hence, autonomy and relatedness are also not understood as ends of a bipolar continuum, but rather as two central human needs that coexist throughout life and mutually influence one another (Guisinger/Blatt 1994). Mature forms of autonomy are characterised by individuals who are aware of their own needs and able to act on them in a self-determined way, yet also able to take the needs of their partner into consideration without feeling their own autonomy to be restricted (Knee et al. 2005). Mature forms of relatedness enable emotional closeness and trust with one's relationship partner without undermining one's own identity. Relationship maturity consequently involves the equal integration of autonomy and relatedness in relationships (Harter et al. 1997; Schultz/Selman 1998). From this perspective, balancing autonomy and relatedness is also necessary for healthy psychological functioning and for the success of intimate relationships (B/att/Blass 1996; Neff/Harter 2002). Here, the perspective of SDT differs from many earlier theories, which assumed that autonomy and relatedness in intimate relationships reflected constant tension or conflict (e.g. Murray 1938). The dialectic perspective of SDT is also confirmed by empirical studies that demonstrate that in the best case, autonomy and relatedness are compatible and mutually beneficial needs in intimate relationships. Hence, there are close, positive correlations between the autonomy and intimacy of partners in adult intimate relationships (Rankin/Esquer et al. 1997) as well as between feelings of autonomy and personal attachment security (La Guardia et al. 2000).

Other theoretical approaches also favour a dialectical perspective of autonomy and relatedness in intimate relationships. For instance, Bakan (1966) describes two basic modalities of human existence - communion and agency - and stresses the necessity of balancing these two aspirations. He assumed that agency, or a focus on the self, must be weakened by a focus on others, or communion, to prevent destructive effects on individuals and society. While Bakan saw communion exclusively as a positive orientation, Helgeson and Fritz (1999) expanded this approach by the concept of unmitigated communion, which is distinguished by the neglect of one's own physical and psychological needs in favour of the needs of others (lack of selffocus) and excessive involvement in the concerns of others (extreme other-focus). They too assessed that balancing the two aspirations for relatedness on the one hand and autonomy on the other is desirable and particularly beneficial for personal 
psychological and physical health and for entering and maintaining satisfying relationships.

On this basis Harter et al. (Harter et al. 1997; Neff/Harter 2002, 2003) eventually developed a theory of relationship styles. They, too, assumed that integrating or balancing autonomy and relatedness in a relationship (mutuality) is the most adaptive way of handling these two needs. This is contrasted by the two less adaptive styles "self-focused autonomy" and "other-focused connectedness", which are characterised by an excessive focus on autonomy or respectively relatedness. Essentially persons with the relationship style of self-focused autonomy behave rather dominantly towards their relationship partner, draw clear boundaries between themselves and their partner, and feel uncomfortable with intimacy (Harter et al. 1997). Other-focused connected persons, by contrast, tend to subordinate themselves in relationships and neglect their own needs, while being very sensitive to the needs and feelings of their partner. People with a balanced relationship style keep their own needs and those of their partner in balance, have flexible boundaries to their partner, are sensitive to their own feelings and those of their partner, and feel secure in their relationship. Using a random sample of over 3,000 adult subjects, Harter et al. showed that $70 \%$ of the participants demonstrated a balanced style, compared to a far smaller percentage of those who over-emphasized either autonomy or relatedness in their relationships. The prevalence of the balanced relationship styles appears to be similarly high among older adults (Harter et al. 1997; Neff/Harter 2002) and among young, college-age adults (Neff/Harter 2003). There were also no detectable gender differences in the distribution of the relationship styles (Harter et al. 1997).

Although the focus of many other theoretical approaches is on the fulfilment of relatedness needs in the context of relationships (Baumeister/ Leary 1995; Drigotas/ Rusbult 1992), the theoretical approaches described here nonetheless show very clearly how central the fulfilment of the needs for autonomy and relatedness in relationships should be considered. In the following, we will first discuss findings that illuminate the significance of autonomy and relatedness for relationship quality and then go into their role in union formation processes.

\subsection{Need satisfaction and relationship quality}

The significance of need satisfaction for functioning intimate relationships has been confirmed by a number of empirical studies. For example in a cross-sectional study Ryan et al. (2005) showed that one's willingness to emotionally trust one's partner was greater the more autonomy and relatedness were reported in the current relationship. Another cross-sectional analysis by Patrick et al. (2007, study 2) of a random sample made up of 66 couples demonstrated that a greater degree of autonomy and relatedness in one's current relationship was associated with greater relationship satisfaction, greater commitment, greater understanding for one's partner during conflicts, less defensive conflict reactions, and a lesser extent of perceived conflict. In addition to these so-called actor effects, or the effects of personal need satisfaction on one's own perception and own behaviour in intimate relationships, Patrick 
et al. (2007, study 2) also ascertained partner effects. The greater the fulfilment of the autonomy and relatedness needs of partner $A$, the greater was the reported relationship satisfaction of partner $B$. An individual's own need satisfaction in the relationship context thus appears not only to be important for personal relationship satisfaction, but also for that of the relationship partner. Studies that are not based on the self-determination theory also revealed effects of need satisfaction on relationship quality and stability. Prager and Burmester (1998) for example showed that the fulfilment of communal needs, such as the need for intimacy, had high positive correlations with relationship satisfaction for both men and for women.

In addition to the fulfilment of the needs for relatedness and autonomy in relationships, the extent to which this is possible in a balanced proportion also appears to play a role. Cross-sectional studies show that the balanced relationship style of "mutuality" was more highly associated with greater relationship satisfaction than the two unbalanced relationship styles "other-focused connectedness" and "selffocused autonomy" (Neff/Harter 2003; Neff/Suizzo 2006). Helgeson and Fritz's empirical studies of the personality styles "unmitigated communion" and "unmitigated agency" had similar results. Persons with excessive orientations towards communion reported excessive involvement in the problems of others and difficulties opening themselves in relationships and asserting their own needs (Fritz/Helgeson 1998). Persons demonstrating unmitigated agency, by contrast, revealed themselves to be dominant and cold (Fritz/Helgeson 1999) and had difficulties expressing their feelings (Helgeson/Lepore 1997). Longitudinally, positive effects of a balance between personal and relationship needs on relationship satisfaction could also be demonstrated six months later (Kumashiro et al. 2008).

\subsection{Need satisfaction and union formation events}

While a large number of studies highlight the influencing factors on relationship quality and stability, only comparatively few provide information about how intimate relationships solidify over the course of their development and what factors are crucial for this process. Intimate relationships go through certain development stages - from the first meeting and falling in love to marriage and starting a family together. In spite of the pluralisation of relationship types and changes in union formation processes, individual union formation events, such as cohabitation, marriage, and starting a family, can still be seen as indicators of a relationship consolidation process. For example, moving in together not only saves money and is more convenient, as often noted (Sass/er 2004), but also helps a couple get to know one another better in view of a possible later marriage. Marriage continues to be the most significant step of union formation, in spite of the fact that marriages are experiencing a documented delay until later in life (Brüderl/Klein 2003). In addition to legal consequences, marriage often also has a symbolic solidifying function and can strengthen the feeling of security and well-being in the relationship (Schneider) Rüger 2007). Starting a family or rather childbirth finally welds the couple together through the obligation to care for the common child and also increases separation costs. 
So, what factors influence the progress of the union formation process and the gradual consolidation of relationships? Previous studies of the determinants of cohabitation or of marriage behaviours primarily focus on socio-structural factors such as education, employment status, or income (Hill/Kopp 1999; Kley/Huinink 2006; Müller 2006). The transition to parenthood also proved to be influenced by socio-structural factors to a significant extent (e.g. Kurz 2005). However, Kopp et al. (2010) additionally emphasize the relevance of relationship quality indicators as possible determinants for union formation processes and thereby refer to Rusbult's Model of Commitment (1983). Hence, the union formation process of a relationship as an "expressive portrayal of personal commitment" (Kopp et al. 2010: 58) benefits from a high relationship satisfaction and high investments already made.

Empirical studies also suggest that indicators of relationship quality are of relevance for the union formation process. For instance, Sass/er (2004) was able to show on the basis of qualitative interviews with 25 cohabitating couples that high relationship quality and frequent nights spent together in one residence prior to moving in together were accompanied by a comparatively rapid transition to cohabitation within six months. In addition, Kopp et al. (2010) found correlations between the couple typologies they formed and the speed of the union formation process. "Burdened" relationships, distinguished by comparatively low future orientation and low relationship satisfaction as well as a high level of conflict, transitioned to cohabitation or engagement relatively slowly. By contrast "harmonious" couples, characterised by high relationship quality, demonstrated far more rapid transitions to cohabitation and engagement. Fowers et al. (1996) also reported that compared to couples with higher relationship qualities, couples with a low amount of functional relationship interaction behaviour and lower satisfaction with the behaviour and habits of the partner (also described as "conflicted") showed a clearly reduced probability of being married three years later. Relationship quality or rather the perceived stability of the intimate relationship also appear to be beneficial factors for the fertility of a couple. However, in most previous studies only the perspective of one of the partners was accounted for (e.g. Myers 1997; Rijken/Liefbroer 2009). For the first time it was Rijken and Thomson (2010), who examined the effects of relationship quality on a couple's fertility from a dyadic perspective. Their study showed that the probability of first childbirth was exclusively positively influenced by the women's perceived relationship quality, whereas the probability of having more children was linked to a positively perceived relationship quality by women and men.

In addition to studies that were able to demonstrate the relevance of relationship quality for union formation processes with relative consistency, there are also restricting findings. For example, although Kopp et al. found a positive cross-sectional correlation between relationship satisfaction and the degree of union formation of the relationship, they found no longitudinal correlation. Surra and Hughes (1997) also showed that relationship satisfaction is only relevant for positive relationship development for some couples, which they described as "relationship-driven". Another group of the couples they studied, whose relationship satisfaction fluctuated 
strongly ("event-driven"), was by contrast more influenced by the progressive consolidation of their relationships by outside events (such as pregnancy).

No study has yet been conducted on the extent to which not only relationship satisfaction, but also need satisfaction, which is closely linked to it, is relevant for the advancement of the union formation of intimate relationships. Taking personal need satisfaction in the relationship into account is quite relevant, however, since today marriage and parenthood are increasingly less normatively prescribed life perspectives. Both have become the object of individual decision-making and relationship negotiating processes. Hence, in light of societal individuation processes (Burkart/Kohli 1989), we can imagine that for the continuation of a relationship and its consolidation through cohabitation, marriage, or childbearing, not only does the need for relatedness has to be fulfilled. Autonomy and self-actualisation in the relationship become prerequisites as well. The results of the cross-sectional study by Patrick et al. (2007) can be deemed indicative of this. They showed that fulfilment of the needs for relatedness and autonomy in a current relationship were accompanied by greater future orientation. A study by Drigotas and Rusbult (1992) also revealed longitudinal effects of the fulfilment of relatedness-oriented needs in relationships on commitment and breakup probability. The higher the relatedness in the relationship, the higher was also the commitment reported by those surveyed and the lower their probability of breaking up. Possibly need satisfaction not only has an influence on relationship commitment processes, but also on commitment-based union formation events, such as cohabitation, marriage, or childbearing.

\section{$3 \quad$ Problems and hypotheses}

The primarily cross-sectional, empirical findings described here suggest that fulfilment and a successful balance of autonomy and relatedness in intimate relationships contribute to positively perceived relationship quality (e.g. Patrick et al. 2007; Neff/Suizzo 2006, Kumashiro et al. 2008). The significance of autonomy and relatedness for the union formation process of intimate relationships has not yet been studied. However, a high degree of autonomy and relatedness fulfilment showed positive effects in relationships on commitment to the partner (Patrick et al. 2007; Drigotas/Rusbult 1992). We therefore assume that high need satisfaction and need balance are beneficial to commitment-based union formation events, such as living together or marriage.

The aim of this study is to examine the longitudinal effects of need satisfaction and balance on relationship quality and on the union formation process. Two competing hypotheses will be tested: the relatedness hypothesis assumes that the fulfilment of the need for relatedness in intimate relationships is more crucial for the function and union formation of relationships than the need for autonomy. The results of the study by Patrick et al. (2007, study 1), which show that relatedness is more closely linked to relationship satisfaction than autonomy, also suggest this. The balance hypothesis by contrast states that equal integration of relatedness and autonomy in a relationship are particularly beneficial for the perceived relationship 
quality and the union formation process of the relationship. In addition to the significance of relatedness, this hypothesis also emphasizes personal self-determination in the relationship - meaning an individuated relationship style characterised by autonomy in relatedness (Williamson 2002). This hypothesis thus takes societal individuation processes into consideration, which are reflected in the increasely autonomy-accentuated relationship forms (such as "living apart together", Hoffmann-Nowotny 1995). Accordingly, an overemphasis of relatedness at the expense of autonomy in the intimate relationship should have rather dysfunctional effects on the formation of the relationship.

Dyadic analyses by Patrick et al. (2007, study 2) suggest that in addition to the described actor effects of need satisfaction, partner effects on relationship quality can also be expected. The research methods of Patrick et al. (2007) did not, however, enable the examination of gender-specific actor and partner effects. Therefore, using dyadic analyses we will first examine gender-specific actor and partner effects of need satisfaction and need balancing on relationship quality. In the process, the validity of the relatedness and the balance hypothesis will also be tested for the partner effects. Additionally, the dyadic design enables the study of gender-specific contributions of need satisfaction on various stages of union formation, as those proven by Rijken and Thomson (2010).

In order to be able to take into account the effects of the concurrent characters of both relationship needs in this study, prior to testing the hypotheses we use cluster analyses to identify types of fulfilment and the balance of autonomy and relatedness in the relationship. Previous studies, particularly those from the perspective of the self-determination theory, almost exclusively examined the singular effects of autonomy or relatedness in the relationship (e.g. Patrick et al. 2007; Ryan et al. 2005). They neglected that the effect of one dimension of need on relationship quality or union formation events could possibly depend on the character of the other need dimension measured at the same time.

\section{$4 \quad$ Method}

\subsection{Random sample}

The data is drawn from the first and second waves of the relationship and family panel survey (pairfam or "Panel Analysis of Intimate Relationships and Family Dynamics"). This is a representative longitudinal study which surveys a random sample of the population of all German-speaking persons living in private households in Germany of three birth cohorts (1991-1993, 1981-1983, and 1971-1973). It is drawn via the registry office and is conducted annually since October 2008. The first survey wave was conducted from the end of 2008 until the beginning of May 2009, the second from mid-October 2009 until mid-April 2010. In addition to the "anchor persons" originating from the random sample, the anchors' partners were also ques- 
tioned if the anchor consented. The anchors were surveyed using computer-based interviews; their partners were assessed via a questionnaire.

Wave 1 (time of interview 1) and wave 2 (time of interview 2) pairfam data were used for the following analyses, whereby only anchor and partner data of couples were included in the random sample if both of the partners took part in both wave 1 and wave 2. Anchors from cohort 1 (young people born 1991-1993) and their partners were excluded from the analyses since, due to their age, only very rare cases of union formation steps taken were to be expected from this group. Thus, the random sample consisted of $\mathrm{N}=3,828$ persons or 1,914 couples.

For 723 couples the anchor was in wave 1 in the age cohort of 25 to 27 -year olds, for 1,191 couples the anchor was in wave 1 in the age cohort of 35 to 37 -year olds. The average age of all persons in the random sample $(\mathrm{N}=3,828)$ at the time of interview 1 was 32.72 (Standard deviation $=5.85$ ). The women were on average 31.34 $(\mathrm{SD}=5.51)$, and the men 34.08 years old $(S D=6.02)$. The average relationship duration of the couples was 112.21 months $(S D=69.27)$ or 9.35 years $(S D=5.77)$. At the time of interview $166.1 \%$ of the couples $(\mathrm{N}=1,266)$ were married, $33.9 \%(\mathrm{~N}=648)$ unmarried. At the time of interview 2 (wave 2) $70.2 \%(\mathrm{~N}=1,344)$ of the couples were married, $29.8 \%(\mathrm{~N}=570)$ unmarried. A very high percentage of the couples $(91.6 \%, N=1,753)$ were living together at the time of interview 1 . At the time of interview 2 the number of cohabitating couples had risen by $2.4 \%$ to $94 \%(N=1,800)$. Moreover, $61.6 \%$ of the couples $(\mathrm{N}=1,172)$ had one or more common children at the time of interview 1 , and in most cases $(N=1,169)$ the child lived together with the couple in a household. $44.6 \%$ of all persons in the random sample $(N=1,706)$ had a higher schooling level (allgemeine Hochschulreife, Fachabitur), $37.3 \%(N=1,428)$ reported an intermediate educational level (Realschulabschluss, mittlere Reife) and $16 \%(N=614)$ a lower educational level (Hauptschulabschluss). $1.7 \%(N=65)$ of the random sample had no school certificate, $0.4 \%(\mathrm{~N}=15)$ cited an educational level that could not be distinctly categorised.

The random sample contains a certain degree of selectivity. Selectivity analyses showed that the partner participation in pairfam wave 1 and wave 2 (compared with the total sample of all persons with partners) is linked to an increased number of persons with Abitur certificates (higher schooling levels) as well as an increased number of cohabitating and married couples. With regard to relationship quality (e.g. relationship satisfaction, intimacy, and autonomy in the relationship) reported by the anchor, however, there were no significant correlations with partner participation to wave 1 or wave 2 .

\subsection{Indicators}

In the following we will describe the indicators employed. A more detailed portrayal of the indicators can be found in the pairfam Scales Manual (Wendt et al. 2011). 


\section{Autonomy and relatedness in the intimate relationship $t_{1}$}

A short indicator consisting of four items from the "Network of Relationship Inventory (NRI)" by Furman and Burmester (1985) was employed to record the relatedness in the current relationship at $t_{1}$. The five-point response format $(1=$ Never, $5=$ Always) refers to the frequency of the occurrence of specific relationship events. These events reflect the subject's personal openness (intimacy scale, e.g. "How often do you share your secrets and private feelings with [name partner]?") or their perceived appreciation by their partner (admiration scale, e.g. "How often does [name partner] show that he/she appreciates you?"). The autonomy scale is based on the "independence" scale, which is part of the Paarklimaskalen (PKS) or "couple climate scales" by Schneewind and Kruse (2002). One of the four items on the scale is new ("I can settle my personal matters by myself without causing conflicts with [name partner]".). With a five-point response format ( $1=$ Not at all, $5=$ Absolutely) the scale measures the extent to which a person feels that they can pursue their own interests without restrictions in their relationship.

\section{Relationship quality $t_{2}$}

The extent of relationship satisfaction at $t_{2}$ was assessed as a central aspect of relationship quality. The satisfaction item ("Overall, how satisfied are you with your relationship?") comes from the German version of the RAS (Relationship Assessment Scale; Hendrick et al. 1998) by Sander and Böcker (1993) and records global satisfaction with one's own relationship by means of an 11-point rating $(0=$ Very dissatisfied to $10=$ Very satisfied). The commitment scale future orientation, which originated from an instrument developed in the scope of the pairfam project based on Grau, Mikula and Engel (2001), was used as a further indicator of relationship quality. This two-item scale records the plans for or expectations of a longer-term, common future as a couple (e.g. "I would like for our partnership to last for a long time".) with a 5-point response format ( $1=$ Not at all, $5=$ Absolutely).

\section{Institutionalisation event between $t_{1}$ and $t_{2}$}

Setting up a household together, marriage, or the birth of a couple's first child between $t_{1}$ and $t_{2}$ were assessed as union formation events. With regard to the birth of the child, it was taken into account that the subjects were not pregnant with this child at $t_{1}$. In addition to the birth of the first common child, a pregnancy reported at $t_{2}$ by the female partner with the first common child was assessed as a transition to parenthood. In addition to the occurrence of the individual union formation events (" 1 " occurred, " 0 " did not occur), a total indicator was formed, which recorded whether one or more union formation events ("1") or no union formation events $\left(" 0\right.$ ") occurred since $t_{1}$.

As Table 1 shows, the scales used resulted in persistently satisfactory reliabilities. 
Tab. 1: Item number, reliabilities, mean values, and standard deviations of the scales used

\begin{tabular}{lccccc}
\hline Scale & Item number & $\begin{array}{c}\text { Cronbach's } \\
\text { Alpha }\end{array}$ & $\begin{array}{c}\text { M (SD) } \\
\text { Total }\end{array}$ & $\begin{array}{c}\text { M (SD) } \\
\text { Men }\end{array}$ & $\begin{array}{c}\text { M (SD) } \\
\text { Women }\end{array}$ \\
\hline Relatedness $t_{1}$ & 4 & .73 & $3.76(.64)$ & $3.72(.62)$ & $3.79(.66)$ \\
Autonomy $t_{1}$ & 4 & .72 & $3.68(.82)$ & $3.45(.79)$ & $3.90(.78)$ \\
Relationship & 1 & - & $8.09(1.99)$ & $8.13(1.90)$ & $8.04(2.06)$ \\
satisfaction $t_{2}$ & 2 & .84 & $4.77(.58)$ & $4.77(.55)$ & $4.76(.62)$ \\
Future orientation $t_{2}$ & & & & &
\end{tabular}

Source: own calculations

\subsection{Methodical procedure}

First, missing values, which made up less than $5 \%$ across all of the variables, were imputed via the EM logarithm using the SPSS module "Missing value analysis". The SPSS statistics program was also used for all other analyses. To ascertain different types of need satisfaction in relationships we first carried out a cluster analysis at the individual level $(\mathrm{N}=3,828)$ using the SPSS module "two-step cluster analyses", in which the two scales of relatedness and autonomy were input. The following analyses were then all conducted at couple level $(N=1,914)$ in order to do justice to the dependencies of the partner data. ANOVA for repeated measurements was employed to test the effects of cluster affiliation of the man or woman on relationship quality. To estimate the effect size, both the significance of the effects and the respective effect intensities were taken into account. According to Bühner and Ziegler (2009), for the effect size measurement eta ${ }^{2}$ partial explanations of variance between 0.01 and 0.06 can be considered low to medium and explanations of variance of 0.06 to 0.14 as medium to high. Cohen's d, which was used in the scope of post-hoc analyses, was interpreted according to Bortz and Döring (2002: 603) at $d=.20$ as a small effect, at $d=.50$ as medium effect and at $d=.80$ as large effect. To test the effects of cluster affiliation at $t_{1}$ on union formation events that occurred between $t_{1}$ and $t_{2}$ logistical regressions were carried out. In addition to the effects of cluster affiliation of the woman and the man on union formation events a size of need satisfaction at the couple level was used to predict union formation events.

\section{$5 \quad$ Results}

\subsection{Cluster analysis}

At the individual level $(\mathrm{N}=3,828)$ a two-step cluster analysis was carried out using the SPSS software program to identify types distinguished by different degrees of relationship autonomy and relatedness at $\mathrm{t}_{1}$. In this way, we were able to identify four clusters (cf. Fig. 1): Cluster 1, to which $13 \%$ of the random sample $(N=496)$ 
could be allocated, is distinguished by clearly lower than average degrees of relationship relatedness $(\mathrm{M}=2.82 ; \mathrm{SD}=.44)$ and autonomy $(2.69 ; \mathrm{SD}=.40)$ at $\mathrm{t}_{1}$ (deficient cluster). Cluster 2 , consisting of 1,028 persons ( $27 \%$ of the random sample), exhibits high autonomy values $(\mathrm{M}=4.01, \mathrm{SD}=.43)$ and comparatively reduced relatedness values $(\mathrm{M}=3.32, \mathrm{SD}=.36$ ) (reduced relatedness cluster). 1,010 persons ( $26 \%$ of the random sample), who demonstrate above average degrees of relatedness $(M=3.99$, $\mathrm{SD}=.36)$ and below average autonomy $(\mathrm{M}=2.96, \mathrm{SD}=.41)$, are allocated to cluster 3 (reduced autonomy cluster). Cluster 4 finally consists of 1,294 persons (34 \% of the random sample) and is characterised by high degrees of autonomy ( $M=4.36$; $\mathrm{SD}=.43$ ) and relatedness $(\mathrm{M}=4,28 ; \mathrm{SD}=.35$ ) (individuated cluster).

A comparison of the results of the different methods of cluster analysis was used to test the validity of the results. For validation, the congruence of the cluster affiliation ascertained using the two-step cluster analysis was calculated with a cluster affiliation ascertained in the scope of a cluster centre analysis (also using SPSS) (cf. Wiedenbeck/Züll 2011). A significant $X^{2}$ test $\left(X^{2}=8023.72, \mathrm{df}=9, \mathrm{p}<.001\right)$ speaks for a non-random distribution of the persons over the individual cells and can therefore be considered an indicator for the desired congruence of the cluster. Additionally, using a cross-classified table congruencies of $75.8 \%$ to $91.9 \%$ were shown between the two-step cluster solution and the cluster centre analysis solution, which indicates good validity. Furthermore, univariate ANOVAs show that the identified clusters differentiate well between different degrees on the scales of autonomy $\left(F=2626.59, \mathrm{df}=3, \mathrm{p}<.001\right.$, eta ${ }^{2}$ artial $\left.=0.67\right)$ and relatedness $(\mathrm{F}=2534.31$, $\mathrm{df}=3, \mathrm{p}<.001$, eta $^{2}$ artial $=0.66$ ). The cluster affiliation explains $67 \%$ of the autonomy scale variance and $66 \%$ of the relatedness scale variance. Post-hoc tests with Bonferroni correction result in significant mean value differences in autonomy between all cluster stages $(p<.001)$. There are small to medium effect sizes for the mean value differences between the deficient and the reduced autonomy cluster (Cohen's $\mathrm{d}=.25$ ) and between the reduced relatedness and the individuated cluster (Cohen's $d=.37$ ) and high effect sizes for the other mean value differences of the autonomy scale ( $d=.76$ to $d=.83$ ). With regard to the relatedness scale post-hoc tests also result in significant differences between all cluster stages $(p<.001)$. For the mean value difference in relatedness between the reduced autonomy and the individuated cluster there is a medium effect size (Cohen's $d=.37$ ), for all other mean value differences between the individual cluster stages high effect sizes are recorded $(\mathrm{d}=.53$ to $\mathrm{d}=.88$ ).

With regard to the distribution of the clusters there are significant gender differences $\left(X^{2}(3)=234.31, p<.001\right.$, cf. Tab. 2). Women exhibit a deficient need satisfaction in the intimate relationship far more infrequently than men ( $N=185 \mathrm{vs}$. $\mathrm{N}=311)$. Also, compared to men, women report an impairment to the fulfilment of their need for autonomy (reduced autonomy cluster: $\mathrm{N}_{\text {women }}=345 \mathrm{vs}$. $\mathrm{N}_{\text {men }}=665$ ) less frequently and are represented to a greater extent in the reduced relatedness cluster $(\mathrm{N}=566$ vs. $\mathrm{N}=462$ ). It also appears easier for them to satisfy both autonomy and relatedness in a balanced proportion. Hence, 818 women are represented in the individuated cluster but only 476 men. These results make clear that men experience less 
Fig. 1: Autonomy and relatedness mean values in the different clusters

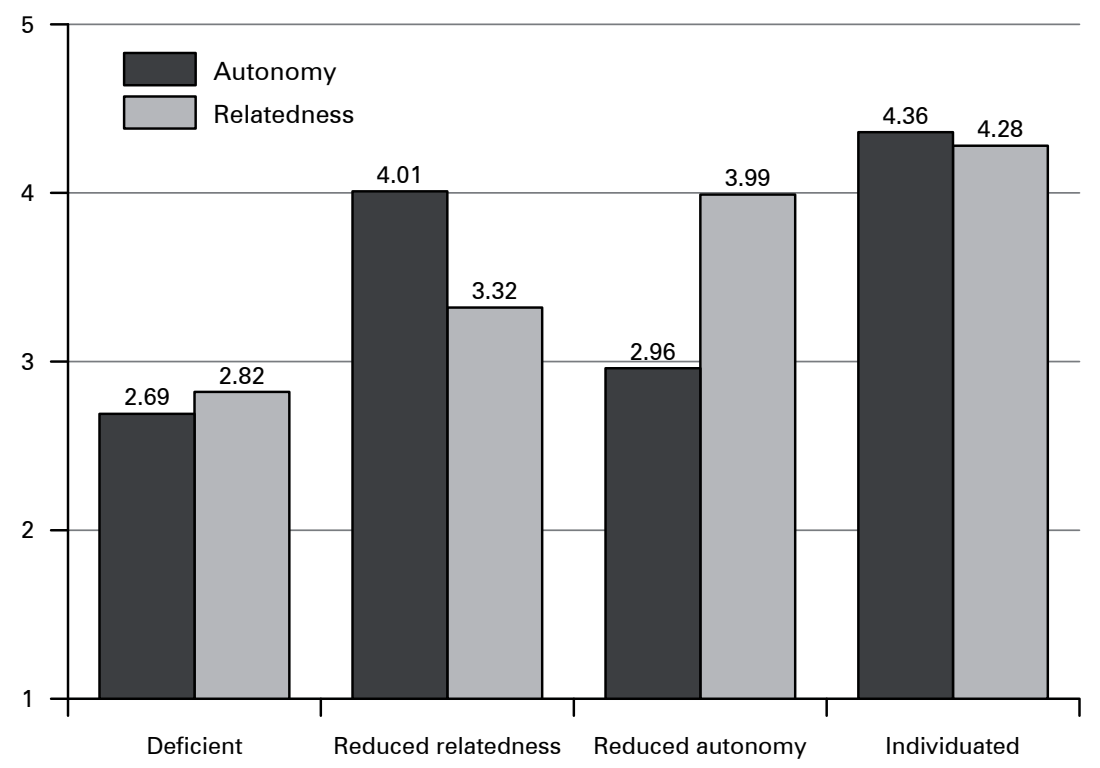

Source: own calculations

autonomy in relationships than women and are therefore less frequent in the clusters that reflect a high fulfilment of the need for autonomy.

Furthermore, there are also significant differences with respect to the distribution of the cluster in the two age cohorts (cohort 2: 25-27 year olds, cohort 3: 35-37 year olds, $\left.X^{2}(3)=73.06, p<.001\right)$. The older cohort reports a balanced fulfilment of the needs for autonomy and relatedness far less frequently $(29.4 \%)$ than the younger age cohort (40.9\%; individuated cluster). By contrast it seems that more persons from the older cohort than from the younger cohort cite reduced relatedness (reduced relatedness cluster: $30.1 \%$ vs. $21.6 \%$ ) and a deficient need satisfaction in the current relationship (deficient cluster: $14.6 \%$ vs. $10.2 \%$ ).

A look at the cluster distribution according to relationship duration results in a similar scenario. There are significant differences in the distribution of the clusters $\left(X^{2}(3)=60.03, p<.001\right)$ between persons with a shorter relationship duration ( 2 years and less) and persons with a longer relationship duration (longer than two years). Persons with a longer relationship duration are represented far less frequently in the individuated cluster $(32.1 \%$ vs. $51.5 \%)$ and far more frequently in the deficient cluster (13.7 \% vs. $5.8 \%)$ and in the reduced relatedness cluster $(27.7 \%$ vs. $18.6 \%)$ than persons with shorter relationship durations.

There are also significant differences in the distributions of the clusters according to educational levels $\left(X^{2}(9)=87.02, p<.001 ;\right.$ Tab. 3). Persons with low educational levels report far more frequently of deficient $(18.7 \%)$ and reduced autonomy need satisfaction in their relationship (33.6\%) than persons with high educational levels (deficient: $10 \%$; reduced autonomy: $23.2 \%$ ). Persons with intermediate and 
Tab. 2: Distribution of the relationship clusters "deficient", "reduced relatedness", "reduced autonomy" and "individuated" in the total sample and according to gender, cohort and relationship duration

\begin{tabular}{lccccccc}
\hline & $\begin{array}{c}\text { Total } \\
\text { sample }\end{array}$ & Women & Men & Cohort 2 & Cohort 3 & $\begin{array}{c}\text { Rel. } \\
\text { Duration } \leq \\
2 \text { yrs. }\end{array}$ & $\begin{array}{c}\text { Rel. } \\
\text { Duration }> \\
2 \text { yrs. }\end{array}$ \\
\hline Deficient & $13,0 \%$ & $9,7 \%$ & $16,2 \%$ & $10,2 \%$ & $14,6 \%$ & $5,8 \%$ & $13,7 \%$ \\
Reduced & $(\mathrm{N}=496)$ & $(\mathrm{N}=185)$ & $(\mathrm{N}=311)$ & $(\mathrm{N}=148)$ & $(\mathrm{N}=348)$ & $(\mathrm{N}=20)$ & $(\mathrm{N}=476)$ \\
relatedness & $27,0 \%$ & $29,6 \%$ & $24,1 \%$ & $21,6 \%$ & $30,1 \%$ & $18,6 \%$ & $27,7 \%$ \\
Reduced & $(\mathrm{N}=1028)$ & $(\mathrm{N}=566)$ & $(\mathrm{N}=462)$ & $(\mathrm{N}=312)$ & $(\mathrm{N}=716)$ & $(\mathrm{N}=64)$ & $(\mathrm{N}=964)$ \\
autonomy & $26,0 \%$ & $18,0 \%$ & $34,7 \%$ & $27,3 \%$ & $25,9 \%$ & $24,1 \%$ & $26,6 \%$ \\
& $(\mathrm{~N}=1010)$ & $(\mathrm{N}=345)$ & $(\mathrm{N}=665)$ & $(\mathrm{N}=349)$ & $(\mathrm{N}=616)$ & $(\mathrm{N}=83)$ & $(\mathrm{N}=927)$ \\
Individuated & $34,0 \%$ & $42,7 \%$ & $24,9 \%$ & $40,9 \%$ & $29,4 \%$ & $51,5 \%$ & $32,1 \%$ \\
& $(\mathrm{~N}=1294)$ & $(\mathrm{N}=818)$ & $(\mathrm{N}=476)$ & $(\mathrm{N}=592)$ & $(\mathrm{N}=702)$ & $(\mathrm{N}=177)$ & $(\mathrm{N}=1117)$ \\
Total & $100 \%$ & $100 \%$ & $100 \%$ & $100 \%$ & $100 \%$ & $100 \%$ & $100 \%$ \\
& $(\mathrm{~N}=3828)$ & $(\mathrm{N}=1914)$ & $(\mathrm{N}=1914)$ & $(\mathrm{N}=1446)$ & $(\mathrm{N}=2382)$ & $(\mathrm{N}=344)$ & $(\mathrm{N}=3484)$ \\
\hline
\end{tabular}

Source: own calculations

Tab. 3: Distribution of the relationship clusters "deficient", "reduced relatedness", "reduced autonomy" and "individuated" in the total sample according to education

\begin{tabular}{lccc}
\hline & $\begin{array}{c}\text { Low educational } \\
\text { level }\end{array}$ & $\begin{array}{c}\text { Intermediate } \\
\text { educational level }\end{array}$ & $\begin{array}{c}\text { High } \\
\text { educational level }\end{array}$ \\
\hline Deficient & $18,7 \%(\mathrm{~N}=127)$ & $13,9 \%(\mathrm{~N}=199)$ & $10,0 \%(\mathrm{~N}=170)$ \\
Reduced relatedness & $22,4 \%(\mathrm{~N}=152)$ & $26,7 \%(\mathrm{~N}=381)$ & $28,8 \%(\mathrm{~N}=492)$ \\
Reduced autonomy & $33,6 \%(\mathrm{~N}=228)$ & $26,8 \%(\mathrm{~N}=383)$ & $23,2 \%(\mathrm{~N}=396)$ \\
Individuated & $25,3 \%(\mathrm{~N}=172)$ & $32,6 \%(\mathrm{~N}=465)$ & $38,0 \%(\mathrm{~N}=648)$ \\
Total & $100 \%(\mathrm{~N}=679)$ & $100 \%(\mathrm{~N}=1428)$ & $100 \%(\mathrm{~N}=1706)$ \\
\hline
\end{tabular}

Source: own calculations

high educational levels are far more frequently represented in the individuated cluster with $32.6 \%$ and $38 \%$ respectively than persons with low educational levels $(25.3 \%)$. Also, in the reduced relatedness cluster there are more frequently persons with intermediate $(26.7 \%)$ and high educational levels $(28.8 \%)$ than persons with low educational levels $(22.4 \%)$. All in all, the findings indicate that persons with low educational levels experience less fulfilment of the need for autonomy in their relationship and are therefore less frequently represented in all clusters characterised by high autonomy in the relationship.

\subsection{Congruence of cluster affiliation between the partners}

An $X^{2}$-test was calculated to test the correlations of cluster affiliation between the partners of a couple. The significant $X^{2}$-coefficient $\left(X^{2}(9)=143.99, p<.001\right)$ indicates 
that there are significant intra-couple correlations with respect to cluster affiliation. For example, women at $\mathrm{t}_{1}$ who cite high autonomy and relatedness (individuated cluster) have increased probability compared with women from other clusters that their partner will also be allocated to the individuated cluster (34\%, see Tab. 4). By contrast, only a very small percentage $(5.4 \%)$ of the women from the deficient cluster has a partner from the individuated cluster. Furthermore, women from the deficient cluster exhibit the highest probability compared with women from other clusters to have a partner who is also allocated to the deficient cluster $(31.9 \%)$. Women from the reduced autonomy cluster exhibit the highest probability compared with the other women to have a partner who also comes from the reduced autonomy cluster $(44.1 \%)$. And reduced relatedness women have the comparatively highest probability to have a partner who is also in the reduced relatedness cluster $(27.9 \%)$. Consequently, the partners exhibit great mutual dependencies in relationship need satisfaction at $t_{1}$. If one of the partners experiences a high extent of autonomy and relatedness in the relationship, there is a comparatively great probability that their partner will also report high need satisfaction. By contrast, an impaired need satisfaction in one partner reduces the chance that the other partner will experience a high extent of autonomy and relatedness in the relationship.

In addition to the autonomy and relatedness clusters as measures of need satisfaction at the individual level, a measure for the need satisfaction at couple level was also formed, whereby the number of fulfilled needs of women and men was used as the basis for classifying the three different couple types. Couples in which both partners cited deficient need satisfaction or in which at most one need (autonomy or relatedness) of one partner was fulfilled were allocated to the couple type "low need satisfaction at couple level" (see Table 4, light-grey shaded couples, $\mathrm{N}=346$ or $18.1 \%$ of all couples). Couples in which each of the partners cited that one need was fulfilled or in which on partner was allocated to the individuated and the other to the deficient cluster were allocated to the couple type "medium need satisfaction at couple level" (medium-grey shading in Tab. $4, \mathrm{~N}=643$ or $33.6 \%$ of all couples). The third couple type "high need satisfaction at couple level" (N=925 or $48.3 \%$ of all couples) included couples in which at least one partner reported fulfilment of autonomy and relatedness, and the respective other partner at least fulfilment autonomy or relatedness (see dark-grey shading in Table 4).

\subsection{Effects of cluster affiliation at $t_{1}$ on relationship satisfaction and future orientation at $t_{2}$}

To test the effects of the man or woman's cluster affiliation on the indicators of relationship quality, a number of $2 \times 4 \times 4$-factorial ANOVAs for repeated measurements were carried out. The cluster affiliation of the man and the woman (4 stages each) were used in the analyses as between-subjects factors. Since the analyses were conducted at the couple level, the gender functions as a repeated measurement factor or as a within-subjects factor (2 stages). Hence, for each dependent variable one measured value each for the woman and the man were used in the analyses. Additionally, the effects of cluster affiliation were examined gender-specifically 
Tab. 4: Intra-couple correlations of the cluster affiliation

\begin{tabular}{|c|c|c|c|c|c|c|c|}
\hline & & & \multicolumn{4}{|c|}{ Woman: autonomy and relatedness cluster $t_{1}$} & \multirow[b]{2}{*}{ Total } \\
\hline & & & Deficient & $\begin{array}{c}\text { Reduced } \\
\text { relatedness }\end{array}$ & $\begin{array}{l}\text { Reduced } \\
\text { autonomy }\end{array}$ & Individuated & \\
\hline \multirow{12}{*}{ 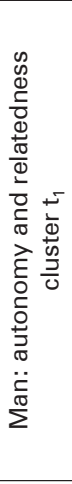 } & \multirow{3}{*}{ Deficient } & Quantity & 59 & 123 & 48 & 81 & 311 \\
\hline & & Expected & 30,1 & 92,0 & 56,1 & 132,9 & 311,0 \\
\hline & & $\begin{array}{l}\% \text { within cluster } \\
\text { woman }\end{array}$ & $31.9 \%$ & $21.7 \%$ & $13.9 \%$ & $9.9 \%$ & $16.2 \%$ \\
\hline & \multirow{3}{*}{$\begin{array}{l}\text { Reduced } \\
\text { relatedness }\end{array}$} & Quantity & 39 & 158 & 70 & 195 & 462 \\
\hline & & Expected & 44.7 & 136.6 & 83.3 & 197.4 & 462.0 \\
\hline & & $\begin{array}{l}\% \text { within cluster } \\
\text { woman }\end{array}$ & $21.1 \%$ & $27.9 \%$ & $20.3 \%$ & $23.8 \%$ & $24.1 \%$ \\
\hline & \multirow{3}{*}{$\begin{array}{l}\text { Reduced } \\
\text { autonomy }\end{array}$} & Quantity & 77 & 172 & 152 & 264 & 665 \\
\hline & & Expected & 64.3 & 196.7 & 119.9 & 284.2 & 665.0 \\
\hline & & $\begin{array}{l}\% \text { within cluster } \\
\text { woman }\end{array}$ & $41.6 \%$ & $30.4 \%$ & $44.1 \%$ & $32.3 \%$ & $34.7 \%$ \\
\hline & \multirow{3}{*}{ Individuated } & Quantity & 10 & 113 & 75 & 278 & 476 \\
\hline & & Expected & 46.0 & 140.8 & 85.8 & 203.4 & 476.0 \\
\hline & & $\begin{array}{l}\% \text { within cluster } \\
\text { woman }\end{array}$ & $5.4 \%$ & $20.0 \%$ & $21.7 \%$ & $34.0 \%$ & $24.9 \%$ \\
\hline \multirow[b]{2}{*}{ Total } & & Quantity & 185 & 566 & 345 & 818 & 1914 \\
\hline & & $\begin{array}{l}\% \text { within cluster } \\
\text { woman }\end{array}$ & $100.0 \%$ & $100.0 \%$ & $100.0 \%$ & $100.0 \%$ & $100.0 \%$ \\
\hline
\end{tabular}

Source: own calculations

and actor and partner effects could be modelled via the interactions between the cluster affiliation of the man and the woman and the repeated measurement factor "gender". Each ANOVA for repeated measurement was controlled by incorporating covariates for the effects of the relationship duration of the couple, the ages of the man and woman and the couple's cohabitation. Furthermore, to control level effects as covariates the $z$-standardised AVs measured at $t_{1}$ were also incorporated. For example, for the ANOVAS with the AV future orientation $t_{2}$ the future orientation of the woman and of the man, measured at $t_{1}$, was recorded as covariate. All post-hoc tests were carried out using Bonferroni correction.

\section{Effects of cluster affiliation $t_{1}$ on relationship satisfaction $t_{2}$}

As seen in Table 5, the main effect of the women's cluster affiliation at $t_{1}(F(3)=31.00$, $p<.001)$ and the main effect of the men's cluster affiliation at $t_{1}(F(3,897)=19.00$, $p<.001$ ) on relationship satisfaction of the couple becomes significant at $t_{2}$. As post-hoc tests show, for the cluster affiliation of the women there are significant mean value differences in the relationship satisfaction of the couple between all cluster stages, except between the deficient and the reduced relatedness cluster. Hence, the relationship satisfaction of couples in which women indicate deficient need satisfaction is significantly lower $(\mathrm{M}=7.01, \mathrm{SE}=.20)$ than in couples in which women indicate reduced autonomy and high relatedness $(\mathrm{M}=7.95, \mathrm{SE}=.12, \mathrm{~d}=.23)$ or fulfilment of autonomy and relatedness $(\mathrm{M}=8.48, \mathrm{SE}=.07, \mathrm{~d}=.47)$. Also, the relationship satisfaction of couples in which women indicate reduced relatedness need satisfaction $(\mathrm{M}=7.54, \mathrm{SE}=.09)$ is significantly lower than that of couples in which 
Tab. 5: ANOVA for repeated measurements: Between-subjects and withinsubjects effects on the AVs relationship satisfaction and future orientation, each measured at $t_{2}$

\begin{tabular}{|c|c|c|c|c|c|c|c|c|c|c|}
\hline & \multicolumn{2}{|c|}{ Cluster woman } & \multicolumn{2}{|c|}{ Cluster man } & \multicolumn{2}{|c|}{ Gender } & \multicolumn{2}{|c|}{$\begin{array}{c}\text { Gender } \\
{ }^{*} \text { cluster woman }\end{array}$} & \multicolumn{2}{|c|}{$\begin{array}{c}\text { Gender } \\
{ }^{*} \text { cluster man }\end{array}$} \\
\hline & $F(3)$ & $\mathrm{Eta}^{2}$ & F (3) & $\mathrm{Eta}^{2}$ & $F(1)$ & $\mathrm{Eta}^{2}$ & $F(3)$ & $\mathrm{Eta}^{2}$ & $F(3)$ & $\mathrm{Eta}^{2}$ \\
\hline $\begin{array}{l}\text { Relationship } \\
\text { satisfaction }\end{array}$ & $31.00^{\star \star \star}$ & .094 & $19.00^{\star \star \star}$ & .060 & .80 & .001 & $6.47^{\star \star \star}$ & .021 & $7.69^{\star \star \star}$ & .025 \\
\hline $\begin{array}{l}\text { Future } \\
\text { orientation }\end{array}$ & $14.76^{\star \star \star}$ & .047 & $12.78^{\star \star \star}$ & .041 & .035 & .000 & $3.93^{\star \star}$ & .013 & $7.86^{\star \star \star}$ & .026 \\
\hline
\end{tabular}

Source: own calculations

women belong to the reduced autonomy cluster $(\mathrm{d}=.12)$ or the individuated cluster $(d=.34)$. And even between the reduced autonomy and the individuated clusters there is a significant mean value difference $(d=.17)$. The significant interaction effect gender* cluster woman $(F(3)=6.47, p<.001)$ reveals that the significant main effect of the cluster affiliation of the women is primarily an actor effect on their personal relationship satisfaction. Hence, among women high need satisfaction of both autonomy and relatedness is linked to the highest personal relationship satisfaction. As Figure 2 shows, although the partner effect is far smaller, men nonetheless also report the highest relationship satisfaction when their partners exhibit high fulfilment of both autonomy and relatedness.

For the significant main effect of the men's cluster affiliation post-hoc analyses show significant mean value differences in the relationship satisfaction of the couple between the deficient cluster and all other clusters and between the individuated cluster and all other clusters. The relationship satisfaction of couples in which the men report deficient need satisfaction is significantly lower $(\mathrm{M}=7.06, \mathrm{SE}=.14)$ than among couples in which the men indicate high autonomy $(\mathrm{M}=7.71, \mathrm{SE}=.11$, $\mathrm{d}=.19)$, high relatedness $(\mathrm{M}=7.94, \mathrm{SE}=.09, \mathrm{~d}=.30)$ or high autonomy and relatedness $(\mathrm{M}=8.27, \mathrm{SE}=.10, \mathrm{~d}=.35)$. There are no significant mean value differences between the reduced relatedness and the reduced autonomy clusters with respect to the couple's relationship satisfaction. The significant interaction in gender ${ }^{*}$ cluster man $\left(F(3)=7.69, p<.001\right.$, eta ${ }^{2}$ partial $\left.=.025\right)$ shows that although an increase is observed in the relationship satisfaction from the deficient to the individuated cluster for both genders, the actor effect is far more intense than the partner effect of the men's cluster affiliation at $\mathrm{t}_{1}$ (see Fig. 2).

\section{Effects of cluster affiliation $t_{1}$ on future orientation $t_{2}$}

The main effects of the women's cluster affiliation $\left(F(3)=14.76, p<.001\right.$, eta ${ }^{2}$ partial $=.047)$ and the men's cluster affiliation $\left(F(3)=12.78, p<.001\right.$, eta ${ }^{2}$ partial $\left.=.041\right)$ on the couple's future orientation at $t_{2}$ become significant. Post-hoc analyses concerning the effects of the cluster affiliation of the women show significant mean value differences in the future orientation of the couple between the deficient $(M=4.36$, 
Fig. 2: $\quad$ Adjusted mean values of the AVs relationship satisfaction t2 and future orientation $t_{2}$ according to the women's relationship typology (left column) and the men at $\mathrm{t}_{1}$ (right column; each controlling the relationship duration of the couple, cohabitation, the age of the woman and of the man and the AV measured at $t_{1}$ )

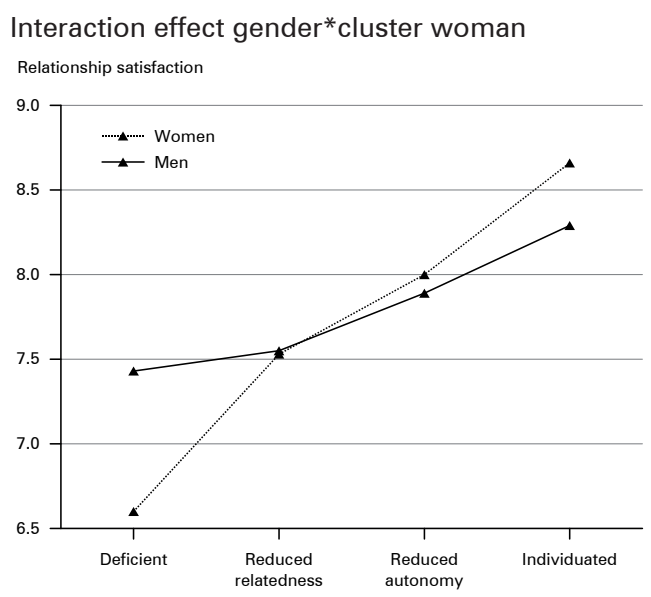

Interaction effect gender* cluster man Relationship satisfaction

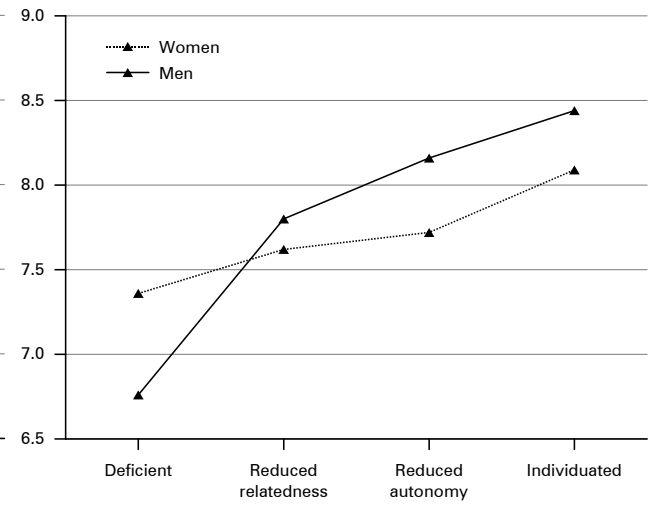

Future orientation
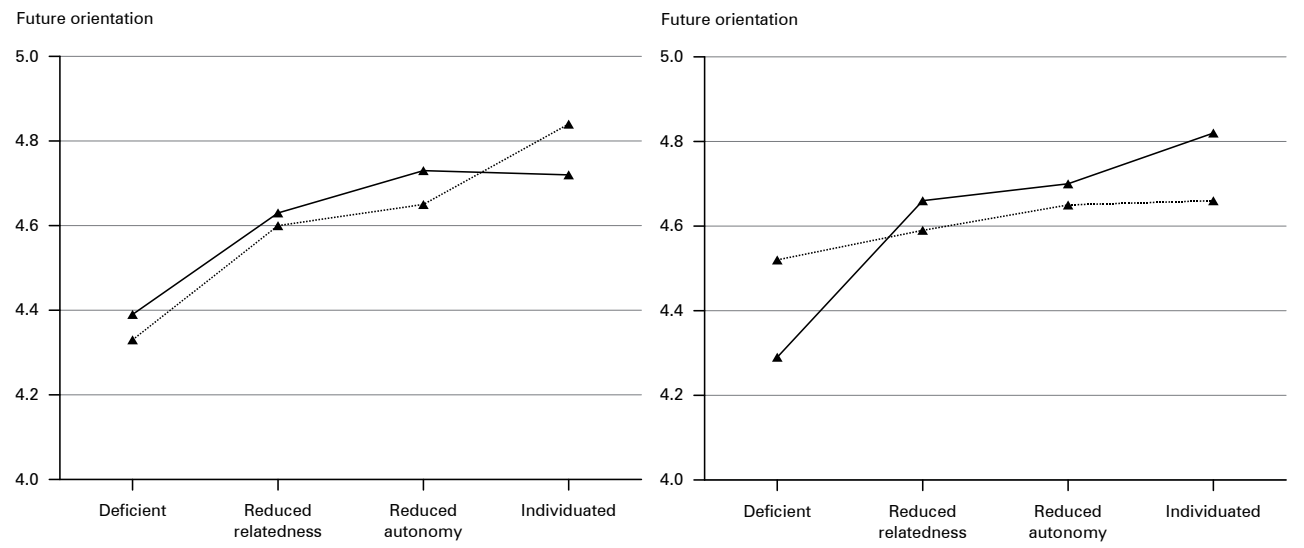

Source: own calculations

$\mathrm{SE}=.07)$ and the reduced relatedness clusters $(\mathrm{M}=4.61, \mathrm{SE}=.03, \mathrm{~d}=.22)$, between the deficient and the reduced autonomy clusters $(M=4.69, S E=.040, d=.25)$ and between the deficient and the individuated clusters $(\mathrm{M}=4.78, \mathrm{SE}=.02, \mathrm{~d}=.41)$. Furthermore, the reduced relatedness cluster also differs significantly from the individuated cluster in the future orientation of the couple $(d=.18)$. The significant interaction gender* ${ }^{*}$ luster woman $\left(F(3)=3.93, p=.008\right.$, eta ${ }^{2}$ partial $\left.=.013\right)$ shows on the other hand that the actor effect of the autonomy and relatedness of the women is greater for their own future orientation at $t_{2}$ than the partner effect is on the future orientation of their partner. Although both their own future orientation and that of the partner increase from the deficient to the reduced autonomy cluster, nonetheless 
high relatedness and autonomy only has an additional positive effect on the future orientation of the women compared with high relatedness and lower autonomy. The post-hoc analyses for the main effect of the cluster affiliation of the men show significant mean value differences in the future orientation of the couple between the deficient $(M=4.41, S E=.05)$ and the reduced relatedness clusters $(M=4.63$, $\mathrm{SE}=.04, \mathrm{~d}=.20)$, between the deficient and the reduced autonomy clusters $(\mathrm{M}=4.68$, $\mathrm{SE}=.03, \mathrm{~d}=.27)$, and between the deficient and the individuated clusters $(\mathrm{M}=4.74$, $\mathrm{SE}=.03, \mathrm{~d}=.29)$. The significant interaction gender ${ }^{*}$ cluster man $(\mathrm{F}(3)=7.86, \mathrm{p}<.001$, eta2partial=.026) also shows that there is only one actor effect of men's autonomy and relatedness on their personal future orientation. Their personal future orientation only drops at $t_{2}$ if men reported deficient autonomy and relatedness in the intimate relationship at $t_{1}$. This effect does not apply to women's future orientation.

\subsection{Effects of $t_{1}$ cluster affiliation on union formation steps between $t_{1}$ and $t_{2}$}

Logistical regressions were carried out to test the effects of cluster affiliation at $t_{1}$ on the occurrence of various union formation steps between $t_{1}$ and $t_{2}$. The dummycoded events "cohabitation", "marriage", and "childbearing" since $\mathrm{t}_{1}$ surveyed at $\mathrm{t}_{2}$ and a dummy-coded total indicator that recorded the occurrence of at least one of these union formation steps between $t_{1}$ and $t_{2}$ function as dependent variables. Different subsamples were used for the dependent variable. To predict the event "cohabitation" a subsample of 161 couples was used who were not yet living together at $\mathrm{t}_{1}$. For the analyses with the dependent variable "marriage" only those couples were taken into account who were not yet married at $t_{1}(n=648)$. And to predict the transition to parenthood a subsample of couples were employed who did not yet have a child together at $t_{1}(n=742)$. In order to predict the occurrence of at least one union formation step since $t_{1}$, logistical regressions were carried out with a subsample of 908 couples who either had not yet moved in together, were not yet married and/or did not have any children together at $t_{1}$. Between $t_{1}$ and $t_{2} a$ total of 62 couples moved in together (39.1\% of all non-cohabitating couples), 82 couples (12.7\% of all non-married couples) had married, and 70 couples $(9.2 \%$ of all couples without children) had become parents or were expecting their first child. At least one of these events occurred between $t_{1}$ and $t_{2}$ for 196 couples $(21.6 \%)$.

Each of the cluster stages was dummy-coded to be able to examine the effects of the cluster affiliation of men and women in the scope of logistical regressions, whereby the individuated cluster served as reference category. Also the control variables education woman, education man, and relationship duration were z-standardised. Table 6 shows the effects of the cluster affiliation of the women and men on the individual union formation events. No significant effects of the cluster affiliation of the women or men can be verified with regard to the union formation events "cohabitation", "marriage", and "transition to parenthood". However, if we look at the odds ratios it becomes clear that single probabilities of union formation events are reduced considerably according to cluster affiliation. For instance, compared with women from the individuated cluster, women from the reduced relatedness cluster 
Tab. 6: Logistical regressions for predicting "cohabitation", "marriage", "transition to parenthood" and the occurrence of at least one of the union formation events; the UVs are the dummy-coded cluster stages of the women and men. Control for education, cohort, and relationship duration. The odds ratios of each predictor are indicated.

\begin{tabular}{|c|c|c|c|c|}
\hline & $\begin{array}{c}\text { Cohabitation } \\
\text { since } t_{1}\end{array}$ & $\begin{array}{l}\text { Marriage } \\
\text { since } t_{1}\end{array}$ & $\begin{array}{c}\text { Transition to } \\
\text { parenthood since } \\
\mathrm{t}_{1}\end{array}$ & $\begin{array}{c}\text { One or more union } \\
\text { formation steps since } \\
t_{1}\end{array}$ \\
\hline Deficient woman $t_{1}$ & .76 & .55 & .31 & .60 \\
\hline $\begin{array}{l}\text { Reduced relatedness } \\
\text { woman } t_{1}\end{array}$ & .54 & 1.05 & .77 & .78 \\
\hline $\begin{array}{l}\text { Reduced autonomy } \\
\text { woman } t_{1}\end{array}$ & .75 & 1.09 & 1.13 & .89 \\
\hline Deficient man $t_{1}$ & .75 & .77 & .58 & .71 \\
\hline $\begin{array}{l}\text { Reduced relatedness } \\
{\text { man } t_{1}}\end{array}$ & .84 & .76 & .69 & $.69+$ \\
\hline $\begin{array}{l}\text { Reduced autonomy } \\
\text { man } t_{1}\end{array}$ & .73 & 1.02 & .84 & .78 \\
\hline Education woman & 1.33 & .93 & 1.00 & 1.11 \\
\hline Education man & 1.14 & 1.11 & .83 & 1.06 \\
\hline $\begin{array}{l}\text { Age cohort 1981-1984 } \\
\text { (Reference: age cohort } \\
\text { 1971-1973) }\end{array}$ & $2.27^{*}$ & 1.37 & .66 & .82 \\
\hline Relationship duration $t_{1}$ & .73 & $2.57^{* *}$ & 1.37 & $.64^{*}$ \\
\hline Nagelkerke's $R^{2}$ & .08 & .05 & .04 & .05 \\
\hline $\mathrm{n}$ & 161 & 648 & 742 & 908 \\
\hline
\end{tabular}

$+p \leq .10,{ }^{*} p \leq .05,{ }^{* *} p \leq .01$; the reference category is "individuated cluster woman" or "individuated cluster man"

Source: own calculations

have an $85.2 \%(O R=.54)$ lesser chance of moving in with their partner. And women from the deficient cluster exhibit an $81.8 \%(O R=.55)$ lesser probability of marrying their partner between $t_{1}$ and $t_{2}$. Women who indicate high autonomy and relatedness at $\mathrm{t}_{1}$ exhibit a $222.58 \%(O R=.31)$ higher probability of becoming mothers for the first time between $t_{1}$ and $t_{2}$ compared with women from the deficient cluster. And men from the deficient cluster have a $72.41 \%(O R=.58)$ lesser chance for the transition to parenthood between $t_{1}$ and $t_{2}$. With regard to the prediction of at least one union formation step since $t_{1}$, there is a marginally significant effect of the reduced relatedness cluster of the man. Compared with couples with individuated men, couples in which men indicate low fulfilment of the relatedness need exhibit a $44.92 \%$ lesser chance $(O R=.69)$ to take one or more union formation steps between $\mathrm{t}_{1}$ and $\mathrm{t}_{2}$.

In spite of the odds ratios, the content of which was considered important, only a single marginally significant effect could be verified. This is probably due to the only very low occupancy of some of the cluster stages in the subsamples. We therefore 
Tab. 7: Logistical regressions for predicting "cohabitation", "marriage", "transition to parenthood" and the occurrence of at least one of the union formation events; the UVs are low or medium need satisfaction at the couple level (reference category high need satisfaction at couple level). Control for education, cohort, and relationship duration. The odds ratios of each predictor are indicated.

\begin{tabular}{lcccc}
\hline & $\begin{array}{c}\text { Cohabitation } \\
\text { since } \mathrm{t}_{1}\end{array}$ & Marriage since $\mathrm{t}_{1}$ & $\begin{array}{c}\text { Transition to } \\
\text { parenthood } \\
\text { since } \mathrm{t}_{1}\end{array}$ & $\begin{array}{c}\text { One or more union } \\
\text { formation steps since } \\
\mathrm{t}_{1}\end{array}$ \\
\hline $\begin{array}{l}\text { Low need satisfaction } \\
\text { couple } \mathrm{t}_{1}\end{array}$ &. $\mathbf{4 8 +}$ &. $\mathbf{5 5 +}$ &. $\mathbf{4 5 +}$ &. $\mathbf{5 4 ^ { * }}$ \\
$\begin{array}{l}\text { Medium need } \\
\text { satisfaction couple } \mathrm{t}_{1}\end{array}$ & .72 & .60 & .88 & $.63^{*}$ \\
$\begin{array}{l}\text { Education woman } \\
\text { Education man }\end{array}$ & 1.26 & .91 & 1.00 & 1.10 \\
$\begin{array}{l}\text { Age cohort 1981-1984 } \\
\text { (Reference age cohort }\end{array}$ & 1.17 & 1.09 & .83 & 1.05 \\
$\begin{array}{l}\text { 1971-1973) } \\
\text { Relationship duration } \mathrm{t}_{1}\end{array}$ & $\mathbf{2 . 1 7 +}$ & 1.44 & .64 & .83 \\
Nagelkerke's $\mathrm{R}^{2}$ & .77 & $\mathbf{2 . 6 7 * *}$ & 1.30 & $.64^{*}$ \\
$\mathrm{n}$ & .07 & .04 & .03 & .05 \\
\hline
\end{tabular}

$+p \leq .10,{ }^{*} p \leq .05,{ }^{* *} p \leq .01$

Source: own calculations

additionally examined the effects of need satisfaction at the couple level using the far more highly occupied couple types formed in Section 5.2. Table 7 shows the results of the logistical regressions, whereby the couple type "high need satisfaction" was used as the reference group to examine the effects of low or medium need satisfaction at the couple level. Compared with couples with high need satisfaction, among couples with lower need satisfaction there are marginal significantly reduced probabilities for cohabitation $(O R=.48)$, marriage $(O R=.55)$, and the transition to parenthood $(O R=.45)$ between $\mathrm{t}_{1}$ and $\mathrm{t}_{2}$. Both for couples with lower and for couples with medium need satisfaction there is a significantly lesser chance for the occurrence of at least one of the three union formation events $(O R=.54$ or $O R=.63$ ) compared with couples with high need satisfaction.

\section{Discussion}

This study made it possible to identify different types of relationship need satisfaction and to demonstrate their significance for relationship quality and the occurrence of union formation events. Cluster analyses were used to find four different types of relationship need satisfaction of significant content. At the time of interview $1,13 \%$ of the random sample reported low, deficient need satisfaction of the 
two needs dimensions of autonomy and relatedness and $27 \%$ reported reduced relatedness need satisfaction. A large part of the random sample $(60 \%)$ indicated either individuated need satisfaction in their relationship, characterised by a balance of autonomy and relatedness, or reduced autonomy, characterised by high relatedness.

There were gender differences in the distribution of the need clusters. There were far less men than women in the reduced relatedness and individuated need clusters, both of which are characterised by high relationship autonomy. Hence, it appears more difficult for men than for women to feel self-determined and autonomous in their relationships. Although prior studies discovered no gender differences in the balance of the autonomy and relatedness orientation in relationships (Harter et al. 1997), women reported significantly higher need satisfaction in autonomy and/ or relatedness in their relationships than men (Patrick et al. 2007). Possibly gender differences in need satisfaction may be because of gender-specific behaviour in intimate relationships. For example, women initiate discussions about relationshiprelevant topics more often than men (Dainton/Stafford 1993) and express their love and affection for their partner more directly and openly (Ragsdale 1996; Stafford et al. 2000). Hence, women appear to advocate the fulfilment of their needs far more actively than men, which may be beneficial to their need satisfaction in the relationship. Moreover, it is also conceivable that women's active, relationship-oriented behaviour not only contributes to greater fulfilment of their own needs for autonomy and relatedness, but is possibly also accompanied by a reduction in the perceived autonomy of their partner. It might also be plausible that compared to women, men have a more autonomous, less relationship-related sense of self (e.g. Cross/Madson 1997), and thus far higher expectations of relationship autonomy which are correspondingly less often fulfilled. The higher percentage of men reporting deficient fulfilment of both needs compared with women also allows for the assumption that men tend more than women to remain in relationships in which central needs are not fulfilled. This would also concur with the results of divorce research, which has shown that women have a far higher probability of initiating separation than men (Hewitt 2009; Kalmijn/Poortman 2006).

In addition to the gender differences in relationship autonomy and relatedness, the study also revealed differences in the distribution of the autonomy and relatedness cluster according to relationship duration. The number of dysfunctional types of need satisfaction (deficient and reduced relatedness types) increased considerably for relationship durations of over two years compared to durations of two or less years. Whereas the number of persons allotted to the individuated cluster was reduced for relationship durations of over two years compared to shorter durations. This concurs with longitudinal studies that were able to prove a diminishment of relationship quality with increasing relationship duration (Clements/Markman 1996; Huston/Holmes 2004).

The educational differences in cluster distribution also appear interesting. For example, there are considerably fewer persons with a low educational level in cluster stages reflecting high autonomy in the relationship (reduced relatedness cluster and individuated clusters) compared with persons with intermediate or high educa- 
tional levels. Hirseland and Leuze (2010) were also able to show that the incidence of individualistic relationship orientations, characterised, for example, by a focus on personal self-actualisation, increases with higher education, however this effect occurred primarily among women. Women with high education appear to be able to "afford" individualistic lifestyles due to their greater financial independence from their partners, whereas women with lower education and lower income put more value on relationship and financial security to the detriment of their own autonomy in the relationship. Subsequent analyses should illuminate whether the educational effect detected also differs gender-specifically in this study.

Persons with low educational levels not only reported lower relationship autonomy, but also deficient need satisfaction in the relationship more frequently than persons with intermediate and high educational levels. Prior studies also showed that couples from lower educational and income strata exhibit lower relationship satisfaction as well as greater levels of conflict and a higher risk of separation (Amato et al. 2007; Lichter et al. 2006). It is possible that the reduced relationship quality and stability of couples from lower educational strata can be explained by the deficient need satisfaction in the relationship identified in this study.

This study was able to confirm that low satisfaction of both need dimensions has a dysfunctional effect on perceived relationship quality. Both women and men who belonged to the deficient need cluster at $\mathrm{t}_{1}$ reported the lowest relationship satisfaction and future orientation at $t_{2}$. Here, the relatedness hypothesis is supported by the fact that relatedness-oriented and reduced autonomy need satisfaction predicted greater personal relationship satisfaction than deficient or reduced relatedness need satisfaction. This applies both for men and for women. By contrast, it seems to be irrelevant for personal future orientation which of the two needs, autonomy and relatedness, is fulfilled. Hence, an impairment of relatedness did not have a negative effect on an individual's being able to envision a long-term future together with their partner as long as the need for autonomy was fulfilled. This result therefore contradicts the relatedness hypothesis and the findings of the meta-analysis by Patrick et al. (2007), which was able to reveal a greater significance of relatedness compared with autonomy for the relationship quality, and also illustrates the relevance of autonomy for the continued course of the relationship.

Nonetheless, we could confirm that for all actor effects on indicators of relationship quality, a balanced fulfilment of both relatedness and autonomy has advantages over the fulfilment of only one need. There was a quite strong additional positive effect of balanced need satisfaction for the relationship satisfaction of men and women. These results thereby confirm the balance hypothesis postulated previously. A number of previous cross-sectional studies (Neff/Harter 2003; Neff/Suizzo 2006) and a longitudinal study (Kumashiro et al. 2008) also showed that a balance of autonomy and relatedness comparably has the most positive effects on relationship quality.

Overall there were greater explanations of variance of the relationship quality indicators measured at couple level at $t_{2}$ for the need satisfaction of the women than for the need satisfaction of the men. The fulfilment of the needs for autonomy and relatedness in the relationship appears more important for the perceived relation- 
ship quality for women than for men. This concurs with current research results that showed that the emotional quality of a relationship is a better separation predictor for women than for men (Nock 2001; Sayer/Bianchi 2000). There are also greater correlations for women between relationship attributes and relationship satisfaction than for men (Aron/Henkemeyer 1995; Morrow et al. 1995).

In addition to actor effects of personal need satisfaction on personal relationship quality, the dyadic design of this study allowed us to also examine and verify partner effects. Primarily the women's need satisfaction exhibited distinct partner effects. For example, partners of women from the deficient cluster at $t_{1}$ reported lower future orientation and relationship satisfaction at $t_{2}$ than partners of women from the individuated need clusters. Conversely, a high, balanced need satisfaction among the men also had positive effects on the relationship satisfaction of the women; however the partner effect was considerably smaller. Therefore, the partner effects also verify the balance hypothesis. Personal need satisfaction appears to not only influence one person's perceived relationship quality, but also that of their partner, as verified in studies by Patrick et al. (2007, study 2) and Deci et al. (2006). These studies additionally showed not only that receiving need support from the partner was accompanied by greater need satisfaction and better relationship outcomes, but also that giving need support had positive effects. Possibly the partners of persons with high fulfilment of autonomy and relatedness also engage more in need-supportive behaviour, such as the expression of appreciation or a willingness to compromise, thereby contributing not only to the high, balanced need satisfaction of their relationship partner, but also to their own wellbeing and a positively perceived relationship quality. But why are there greater partner effects for the need satisfaction of women than of men? Perhaps women are more open in addressing that their needs in the relationship are not fulfilled than men (Ragsdale 1996; Stafford/Dainton/Haas 2000) or allow their partners to participate more in their happiness about positive need satisfaction. Through this more open manner of dealing with relationship-related needs and feelings, women perhaps also have more of an influence on the partner's perceived relationship quality than vice versa.

While the significance of need satisfaction for relationship quality has already been analysed in a number of mainly cross-sectional studies, so far there have been no empirical studies assessing the relevance of both autonomy and relatedness for the union formation process. This study was able to close this research gap and for the first time verify empirically that couples with low need satisfaction tend to exhibit a reduced probability for cohabitation, marriage, or the transition to parenthood in the next year compared with couples with high relationship need satisfaction. The chance of the occurrence of one of more union formation steps in the following year was also reduced for couples with medium need satisfaction (compared with couples with high need satisfaction). If we consider the union formation process of relationships as an expression of relationship commitment, it seems only logical that need satisfaction not only influences commitment (Patrick et al. 2007, study 2; Drigotas/Rusbult 1992), but also influences commitment-based union formation steps taken by the couple. A lack of need satisfaction appears to impair the willingness to enter into a long-term relationship commitment and the 
union formation steps associated with it. Previous studies already indicate that aspects of relationship quality are relevant for cohabitation (Sass/er 2004), marriage (Fowers et al. 1996; Kopp et al. 2010), and the transition to parenthood (Myers 1997; Rijken/Thomson 2010). Against the background of an increasingly more individualised society is appears quite comprehensible that personal need satisfaction in the intimate relationship is also relevant for the union formation process of the relationship. Personal self-actualisation and added emotional benefits have become central demands on intimate relationships (Nave-Herz 1990; Weiss 1995) and therefore also the prerequisites for being open to consolidating the relationship through cohabitation, marriage, and childbearing.

The differential significance of relationship autonomy and/or relatedness for the union formation process of the relationship could not be explained on the basis of the couple typology since we were not able to conduct a corresponding differentiation of the compared groups. The gender-specific study of effects of each of the autonomy and relatedness clusters on union formation events results in only a marginally significant effect due to partially low occupancy of the cluster stages in the subsamples used. There is evidence that when the man reports reduced relatedness in the relationship this marginally significantly reduces the probability for the occurrence of one or more union formation events in the following year, whereby the individuated need satisfaction functioned as the reference category. The fact that besides reduced relatedness also a low fulfilment of autonomy needs in the relationship is relevant for the union formation process is reflected in the significant content yet insignificant effects of deficient need satisfaction. For example, women with deficient need satisfaction exhibit a considerably reduced probability of marrying or having their first child with their partner in the following year. Similarly, couples in which men experience deficient need satisfaction in the relationship have a reduced probability of transition to parenthood. This finding emphasizes the relevance of the man's perceived relationship quality for the fertility of the couple and contradicts the results of Rijken and Thompson (2010) that showed that only the relationship satisfaction of the woman, but not that of the man is relevant for the transition to parenthood. Nevertheless we must note that the gender-specific effects of need satisfaction on union formation events resulted only in tentatively significant effects. The discrepancy between the mostly quite substantial odds ratios and the lacking significance of the results is probably due to the rare occurrence of union formation events and the low group size in the deficient cluster.

For women and men, there were no significant differences in the probability of the occurrence of the various union formation events between the simultaneous fulfilment of both autonomy and relatedness and the exclusive fulfilment of relatedness concurrent with low autonomy in the relationship. This can be assessed as an indication that primarily the fulfilment of the relatedness need is relevant for the union formation process of the relationship and that the balance hypothesis is not verified in this context.

Although this study was able to identify meaningful types of relationship need satisfaction and thereby enabled us to examine the combined effects of the simultaneous occurrence of autonomy and relatedness in the relationship, the singular 
actor and partner effects of autonomy and relatedness remained unexplained. In order to better understand this effect additional analyses are needed at the individual scale level in future. A certain selectivity of the random sample was another restriction. Hence, the sample of couples is comparatively "institutionalised" since partner participation records a higher number of cohabitating and married couples. This may have led to distortions primarily in conjunction with the analyses of various union formation events. Non-dyadic analyses that are not linked to the participation of the partner will therefore be needed in future to be able to interpret the relevance of these results. Furthermore, the merely small to medium explanations of variance by the autonomy and relatedness types show that there are a number of further influencing factors on personal wellbeing and relationship quality, which were not incorporated in the existing analyses. Therefore, against the background of the gender and relationship duration differences in the distribution of the autonomy and relatedness types ascertained, it would be interesting to more closely illuminate the determinants of the need satisfaction in future. For example, it is conceivable that motives developed biographically, personality factors, and contextual factors such as stressors influence personal need satisfaction and thereby cause gender differences in need satisfaction. An examination of the conditions of relationship need satisfaction could also contribute to identifying starting points for relationship therapy interventions to promote perceived autonomy and relatedness in the relationship. Systematic integration of such couple interventions aimed at promoting need satisfaction in the scope of relationship counselling and therapy appear expedient and necessary in light of the proven relevance of need satisfaction for relationship quality and the union formation process of the couple.

\section{References}

Amato, Paul R.; Booth, Alan; Johnson, David R.; Rogers, Stacy J. 2007: Alone together: How marriage in America is changing: Harvard University Press.

Angyal, Andras 1951: A theoretical model for personality studies: Wiley Online Library.

Aron, Arthur; Henkemeyer, Lisa 1995: Marital satisfaction and passionate love. In: Journal of Social and Personal Relationships 12,1: 139-146 [doi: 10.1177/0265407595121010]

Baard, Paul P.; Deci, Edward L.; Ryan, Richard M. 2004: Intrinsic need satisfaction: A motivational basis of performance and well being in two work settings. In: Journal of Applied Social Psychology 34,10: 2045-2068 [doi: 10.1111/j.1559-1816.2004.tb02690.x].

Bakan, David 1966: The duality of human existence: An essay on psychology and religion. Chicago: Rand McNally

Baumeister, Roy F.; Leary, Mark R. 1995: The need to belong: Desire for interpersonal attachments as a fundamental human motivation. In: Psychological Bulletin 117,3: 497-529 [doi: 10.1037/0033-2909.117.3.497].

Berscheid, Ellen; Regan, Pamela C. 2005: The psychology of interpersonal relationships: Pearson Prentice Hall. 
Blatt, Sidney J.; Blass, Rache/ B. 1996: Relatedness and self-definition: A dialectic model of personality development. In: Noam, Gil G.; Fischer, Kurt W. (Eds.): Development and vulnerability in close relationships. New Jersey: Laurence Erlbaum Associates: 309-338.

Bortz, Jürgen; Döring, Nicola 2006: Forschungsmethoden und Evaluation für Humanund Sozialwissenschaftler. Berlin Springer.

Braithwaite, Scott R.; Delevi, Raquel; Fincham, Frank D. 2010: Romantic relationships and the physical and mental health of college students. In: Personal Relationships 17,1: 1-12 [doi: 10.1111/j.1475-6811.2010.01248.x].

Brüderl, Josef; Klein, Thomas 2003: Die Pluralisierung partnerschaftlicher Lebensformen in Westdeutschland, 1960-2000. In: Bien, W.; Marbach, J. (Eds.): Partnerschaft und Familiengründung. Opladen: 189-217.

Burkart, Günter; Kohli, Martin 1989: Ehe und Elternschaft im Individualisierungsprozeß: Bedeutungswandel und Milieudifferenzierung. In: Zeitschrift für Bevölkerungswissenschaft 15: 405-426.

Bühner, Markus; Ziegler, Matthias 2009: Statistik für Psychologen und Sozialwissenschaftler: Pearson Studium.

Clements, Mari; Markman, Howard J. 1996: The transition to parenthood: Is having children hazardous to marriage? In: Vanzetti, Nelly; Duck, Steve (Eds.): A lifetime of relationships. Belmont: Thomson Brooks/Cole Publishing: 290-310.

Cross, Susan E.; Madson, Laura 1997: Models of the self: Self-construals and gender. In: Psychological Bulletin 122,1: 5-37 [doi: 10.1037/0033-2909.122.1.5].

Dainton, Marianne; Stafford, Laura 1993: Routine maintenance behaviors: A comparison of relationship type, partner similarity and sex differences. In: Journal of Social and Personal Relationships 10,2: 255-271 [doi: 10.1177/026540759301000206].

Deci, Edward L.; La Guardia, Jennifer G.; Moller, Arlen C.; Scheiner, Marc J.; Ryan, Richard M. 2006: On the benefits of giving as well as receiving autonomy support: Mutuality in close friendships. In: The Society for Personality and Social Psychology 32,3: 313-327 [doi: 10.1177/0146167205282148].

Deci, Edward L.; Ryan, Richard M. 2000: The "What" and „Why" of goal pursuits: Human needs and the self-determination of behavior. In: Psychological Inquiry 11,4: 227-268 [doi: 10.1207/S15327965PLI1104_01].

Drigotas, Stephen M.; Rusbult, Caryl E. 1992: Should I stay or should I go? A dependence model of breakups. In: Journal of Personality and Social Psychology 62,1: 62-87 [doi: 10.1037/0022-3514.62.1.62].

Fowers, Blaine J.; Montel, Kelly H.; Olson, David H. 1996: Predicting marital success for premarital couple types based on PREPARE. In: Journal of Marital and Family Therapy 22: 02-120 [doi: 10.1111/j.1752-0606.1996.tb00190.x].

Franz, Carol E.; White, Kathleen M. 1985: Individuation and attachment in personality development: Extending Erikson's theory. In: Journal of Personality 53,2: 224-256 [doi: 10.1111/j.1467-6494.1985.tb00365.x].

Fritz, Heidi L.; Helgeson, Vicky S. 1998: Distinctions of Unmitigated Communion From Communion: Self-Neglect and Overinvolvement With Others. In: Journal of Personality and Social Psychology 75,1: 121-140 [doi: 10.1037/0022-3514.75.1.121].

Furman, Wyndol; Buhrmester, Duane 1985: Children's perception of the qualities of sibling relationships. In: Child Development 56: 448-461 [doi: 0009-3920/ 85/5602-0017\$01.00]. 
Grau, Ina; Mikula, Gerold; Engel, Susanne 2001: Skalen zum Investitionsmodell von Rusbult. In: Zeitschrift für Sozialpsychologie 32: 29-44 [doi: 10.1024//0044-3514.32.1.29].

Guisinger, Shan; Blatt, Sidney 1994: Individuality and relatedness: Evolution of a fundamental dialectic. In: American Psychologist 49,2: 104-111 [doi: 10.1037/0003-066X.49.2.104]

Harter, Susan; Waters, Patricia L.; Pettitt, Lisa M.; Whitesell, Nancy; Kofkin, Jennifer; Jordan, Judith 1997: Autonomy and connectedness as dimensions of relationships styles in men and woman. In: Journal of Social and Personal Relationships 14,2: 147-164 [doi: 10.1177/0265407597142001].

Helgeson, Vicki S. 1994: Relation of agency and communion to well-being: Evidence and potential explanations. In: Psychological Bulletin 116,3: 412-428 [doi: 10.1037/0033-2909.116.3.412 ].

Helgeson, Vicki S.; Fritz, Heidi L. 1999: Unmitigated agency and unmitigated communion: Distinctions from agency and communion. In: Journal of Research in Personality 33,2: 131-158 [doi: 10.1006/jrpe.1999.2241].

Helgeson, Vicki S.; Lepore, Stephen J. 1997: Men's adjustment to prostate cancer: The role of agency and unmitigated agency. In: Sex roles 37,3: 251-267 [doi: 10.1023/A:1025651912128].

Hendrick, Susan S.; Dicke, Amy; Hendrick, Clyde 1998: The relationship assessment scale. In: Journal of Social and Personal Relationships 15,1: 137-142 [doi: 10.1177/0265407598151009].

Hewitt, Belinda 2009: Which spouse initiates marital separation when there are children involved? In: Journal of Marriage and Family 71,2: 362-372 [doi: 10.1111/j.17413737.2009.00603.x].

Hill, Paul B.; Kopp, Johannes 1999: Nichteheliche Lebensgemeinschaften - theoretische Aspekte zur Wahl von Lebensformen. In: Klein, Thomas; Lauterbach, Wolfgang (Eds.): Nichteheliche Lebensgemeinschaften. Opladen: Leske + Budrich: 11-35.

Hirseland, Andreas; Leuze, Kathrin 2010: Jenseits der traditionellen Paarbeziehung? In: Berger, Peter A.; Hitzler, Ronald (Eds.): Individualisierungen. VS Verlag: 191-209.

Hoffmann-Nowotny, Hans-Joachim 1995: Die Zukunft der Familie - die Familie der Zukunft. In: Gerhardt, Uta; Hradil, Stefan; Lucke, Doris; Nauck, Bernhard (Eds.): Familie der Zukunft. Lebensbedingungen und Lebensformen. Opladen: 325-348.

Huston, Ted L.; Holmes, Erin Kramer 2004: Becoming parents. In: Vangelisti, Anita L. (Ed.): Handbook of family communication. New Jersey: Lawrence Erlbaum Associates: 105-133.

Kalmijn, Matthijs; Poortman, Anne-Rigt 2006: His or her divorce? The gendered nature of divorce and its determinants. In: European sociological review 22,2: 201-214 [doi: 10.1093/esr/jci052].

Kley, Stefanie; Huinink, Johannes 2006: Die Gründung des eigenen Haushalts bei Ostund Westdeutschen nach der Wiedervereinigung. In: Zeitschrift für Bevölkerungswissenschaft 31,1: 127-154.

Knee, C. Raymond; Lonsbary, Cynthia; Canevello, Amy; Patrick, Heather 2005: Self-determination and conflict in romantic relationships. In: Journal of Personality and Social Psychology 89,6: 997-1009 [doi: 10.1037/0022-3514.89.6.997].

Kopp, Johannes; Lois, Daniel; Becker, Oliver Arránz; Kunz, Christina 2010: Verliebt, verlobt, verheiratet: Institutionalisierungsprozesse in Partnerschaften: VS Verlag [doi: 10.1007/978-3-531-92304-8]. 
Kumashiro, Madoka; Rusbult, Caryl E.; Finkel, Eli J. 2008: Navigating personal and relational concerns: The quest for equilibrium. In: Journal of Personality and Social Psychology 95,1: 94-110 [doi: 10.1037/0022-3514.95.1.94].

Kurz, Karin 2005: Die Familiengründung von Männern im Partnerschaftskontext. In: Tö/ke, Angelika; Hank, Karsten (Eds.): Männer - Das „vernachlässigte“ Geschlecht in der Familienforschung. Wiesbaden: 178-197.

La Guardia, Jennifer G.; Patrick, Heather 2008: Self-determination theory as a fundamental theory of close relationships. In: Canadian Psychology 49,3: 201-209 [doi: 10.1037/a0012760].

La Guardia, Jennifer G.; Ryan, Richard M.; Couchman, Charles E.; Deci, Edward L. 2000: Within-person variation in security of attachment: A self-determination theory perspective on attachment, need fulfillment, and well-being. In: Journal of Personality and Social Psychology 79,3: 367-384 [doi: 10.1037/0022-3514.79.3.367].

Lichter, Daniel T.; Qian, Zhenchao; Mellott, Leanna M. 2006: Marriage or dissolution? Union transitions among poor cohabiting women. In: Demography 43,2: 223-240 [doi: 10.1353/dem.2006.0016].

Lucas, Richard E.; Dyrenforth, Portia S. 2006: Does the existence of social relationships matter for subjective well-being? In: Vohs, Kathleen D.; Finkel, Eli J. (Eds.): Self and relationships: Connecting intrapersonal and interpersonal processes. New York: Guilford Press: 254-273.

Maslow, Abraham 1955: Deficiency motivation and growth motivation. In: Jones, Marshall $R$. (Ed.): Nebraska symposium on motivation: 1955. Lincoln, NE: University of Nebraska Press: 1-30.

McClelland, David C. 1985: How motives, skills, and values determine what people do. In: American Psychologist 40,7: 812-825 [doi: 10.1037/0003-066X.40.7.812].

McClelland, David C.; Atkinson, John W.; Clark, Russell A.; Lowell, Edgar L. 1953: The achievement motive. New York: Appleton-Century-Crofts.

Morrow, Gregory D.; Clark, Eddie M.; Brock, Karla F. 1995: Individual and partner love styles: Implications for the quality of romantic involvements. In: Journal of Social and Personal Relationships 12,3: 363-387 [doi: 10.1177/0265407595123003].

Müller, Rolf 2006: Wandel der Rolle der Frau und Auflösung der Institution Ehe: Bremen, RMInt Soziologisches Forschungsinstitut und Verlag.

Murray, Henry A. 1938: Explorations in personality. Oxford: Oxford University Press.

Myers, Scott M. 1997: Marital uncertainty and childbearing. In: Social Forces 75: 1271-1289 [doi: 10.1093/sf/75.4.1271].

Nave-Herz, Rosemarie 1990: Scheidungsursachen im Wandel. Bielefeld: Kleine.

Neff, Kristin D.; Harter, Susan 2002: The role of power and authenticity in relationship styles emphasizing autonomy, connectedness, or mutuality among adult couples. In: Journal of Social and Personal Relationships 19,6: 835-857 [doi: 10.1177/0265407502196006].

Neff, Kristin D.; Harter, Susan 2003: Relationship styles of self-focused autonomy, otherfocused connectedness, and mutuality across multiple relationship contexts. In: Journal of Social and Personal Relationships 20,1: 81-99 [doi: 10.1177/02654075030201004].

Neff, Kristin D.; Suizzo, Marie-Anne 2006: Culture, power, authenticity and psychological well-being within romantic relationships: A comparison of European American and Mexican Americans. In: Cognitive Development 21,4: 441-457 [doi: doi:10.1016/j. cogdev.2006.06.008]. 
Nock, Steven L. 2001: The marriages of equally dependent spouses. In: Journal of Family Issues 22,6: 755-775 [doi: 10.1177/019251301022006005].

Oesterdiekhoff, Georg W.; Jegelka, Norbert 2001: Werte und Wertewandel in westlichen Gesellschaften: Opladen, Leske+Budrich.

Patrick, Heather; Knee, C. Raymond; Canevello, Amy; Lonsbary, Cynthia 2007: The role of need fulfillment in relationship functioning and well-being: A self-determination theory perspective. In: Journal of Personality and Social Psychology 92,3: 434-457 [doi: 10.1037/0022-3514.92.3.434].

Peuckert, Rüdiger 2008: Familienformen im sozialen Wandel. Wiesbaden: VS Verlag.

Prager, Karen J.; Buhrmester, Duane 1998: Intimacy and need fulfillment in couple relationships. In: Journal of Social and Personal Relationships 15: 435-465 [doi: 10.1177/0265407598154001].

Ragsdale, J. Donald 1996: Gender, satisfaction level, and the use of relational maintenance strategies in marriage. In: Communication Monographs 63,4: 354-369 [doi: 10.1080/03637759609376399].

Rankin Esquer, Lynn A.; Burnett, Charles K.; Baucom, Donald H.; Epstein, Norman 1997: Autonomy and relatedness in marital functioning. In: Journal of Marital and Family Therapy 23,2: 175-190 [doi: 10.1111/j.1752-0606.1997.tb00242.x].

Rijken, Arieke J.; Liefbroer, Aart C. 2009: The influence of partner relationship quality on fertility. In: European Journal of Population 25,1: 27-44 [doi: 10.1007/ s10680-008-9156-8].

Rijken, AriekeJ.; Thomson, Elizabeth 2010: Partners' relationship quality and childbearing. In: Social Science Research 40,2: 485-497 [doi: 10.1016/j.ssresearch.2010.10.001].

Rusbult, CarylE. 1983: A longitudinal test of the investment model: The development (and deterioration) of satisfaction and commitment in heterosexual involvements. In: Journal of Personality and Social Psychology 45,1: 101-117 [doi: 10.1037/0022-3514.45.1.101].

Ryan, Richard M. 1995: Psychological needs and the facilitation of integrative processes. In: Journal of Personality 63,3: 397-427 [doi: 10.1111/j.1467-6494.1995.tb00501.x].

Ryan, Richard M. 1993: Agency and organization: Intrinsic motivation, autonomy and the self in psychological development. In: Jacobs, Janis (Ed.): Nebraska symposium on motivation: Developmental perspectives on motivation. Lincoln, NE University of Nebraska Press: 1-56.

Ryan, Richard M.; Deci, Edward L. 2000: Self-determination theory and the facilitation of intrinsic motivation, social development, and well-being. In: American Psychologist 55,1: 68-78 [doi: 10.1037/0003-066X.55.1.68].

Ryan, Richard M.; Deci, Edward L. 2008: Self-determination theory and the role of basic psychological needs in personality and the organization of behavior. In: John, Oliver P.; Robins, Richard W.; Pervin, Lawrence A. (Eds.): Handbook of personality: Theory and research. New York: Guilford Press: 654-678.

Ryan, Richard M.; La Guardia, Jennifer G.; Solky-Butzel, Jessica; Chirkov, Valery; Kim, Youngmee 2005: On the interpersonal regulation of emotions: Emotional reliance across gender, relationships, and cultures. In: Personal Relationships 12,1: 145-163 [doi: 10.1111/j.1350-4126.2005.00106.x].

Sander, Joachim; Böcker, Susanne 1993: Die deutsche Form der Relationship Assessment Scale (RAS): Eine kurze Messung der Zufriedenheit in der Partnerschaft. In: Diagnostica 39,1: 55-62. 
Sassler, Sharon 2004: The process of entering into cohabiting unions. In: Journal of Marriage and Family 66,2: 491-505 [doi: 10.1111/j.1741-3737.2004.00033.x].

Sayer, Liana C.; Bianchi, Suzanne M. 2000: Women's economic independence and the probability of divorce. In: Journal of Family Issues 21,7: 906-943 [doi: 10.1177/019251300021007005].

Schneewind, Klaus A.; Kruse, Joachim 2002: Die Paarklimaskalen (PKS). Bern: Huber.

Schneider, Norbert F.; Rüger, Heiko 2007: Value of Marriage. Der subjektive Sinn der Ehe und die Entscheidung zur Heirat. In: Zeitschrift für Soziologie 36,2: 131-152.

Schultz, Lynn H.; Selman, Robert L. 1998: Ego development and interpersonal development in young adulthood: A between-model comparison. In: Westenberg, P. Michiel; Blasi, Augusto; Cohn, Lawrence D. (Eds.): Personality development: Theoretical, empirical, and clinical investigations of Loevinger's conception of ego development. Hillsdale, NJ: Lawrence Erlbaum: 181-202.

Stafford, Laura; Dainton, Marianne; Haas, Stephen 2000: Measuring routine and strategic relational maintenance: Scale revision, sex versus gender roles, and the prediction of relational characteristics. In: Communication Monographs 67,3: 306-323 [doi: 10.1080/03637750009376512].

Surra, Catherine A.; Hughes, Debra K. 1997: Commitment processes in accounts of the development of premarital relationships. In: Journal of Marriage and Family 59,1: 5-21.

Weiss, Hilde 1995: Liebesauffassungen der Geschlechter. In: Soziale Welt 46: 119-137.

Wendt, Eva-Verena; Schmahl, Franziska; Thönnissen, Carolin; Schaer, Markus; Walper, Sabine 2011: Pairfam Scales Manual, Wave 1 \& 2. http://www.pairfam.uni-bremen.de/ fileadmin/user_upload/redakteur/publis/Dokumentation/pairfam_welle_2/pairfam_ scales_manual_en_waves_1_2.pdf, 05.07.2011.

Whisman, Mark A. 2007: Marital distress and DSM-IV psychiatric disorders in a population-based national survey. In: Journal of Abnormal Psychology 116,3: 638-643 [doi: 10.1037/0021-843x.116.3.638].

Wiedenbeck, Michael; Züll, Cornelia 2001: Klassifikation mit Clusteranalyse: Grundlegende Techniken hierarchischer und K-means-Verfahren. In: ZUMA how-to-Reihe 10: 1-18.

Williamson, Donald S. 2002: The intimacy paradox: Personal authority in the family system. New York: The Guilford Press. 
Translated from the original text by the Federal Institute for Population Research, for information only. The reviewed and author's authorised original article in German is available under the title "Nur die Verbundenheit zählt? Die Bedeutung partnerschaftlicher Bedürfniserfüllung für die Qualität und fortschreitende Institutionalisierung von Paarbeziehungen", DOI 10.4232/10.CPoS-201201de or URN urn:nbn:de:bib-cpos-2012-01de6, at http://www.comparativepopulationstudies.de.

Date of submission: 26.10 .2011

Date of Acceptance: 15.03 .2012

Dipl.-Psych. Franziska Schmahl ( $₫)$. Institut für Pädagogik, Ludwig-MaximiliansUniversität München, Martiusstr. 4, 80802 Munich. Germany

E-Mail: Franziska.Schmahl@edu.Imu.de. URL: http://www.edu.Imu.de/apb/personen/ wiss_ma/schmahl/index.html

Prof. Sabine Walper. Institut für Pädagogik, Ludwig-Maximilians-Universität München, Leopoldstr. 11, 80802 Munich. Germany

E-Mail: Sabine.Walper@edu.Imu.de.URL: http://www.edu.Imu.de/apb/personen/ professoren/walper/index.html 


\section{Comparative Population Studies - Zeitschrift für Bevölkerungswissenschaft}

wWw.comparativepopulationstudies.de

ISSN: 1869-8980 (Print) - 1869-8999 (Internet)

Published by / Herausgegeben von

Prof. Dr. Norbert F. Schneider

Federal Institute for Population Research

D-65180 Wiesbaden / Germany

Managing Editor /

Verantwortlicher Redakteur

Frank Swiaczny

Editorial Assistant /

Redaktionsassistenz

Katrin Schiefer

Language \& Copy Editor (English) /

Lektorat \& Übersetzungen (englisch)

Amelie Franke

Copy Editor (German) /

Lektorat (deutsch)

Dr. Evelyn Grünheid

Layout / Satz

Sybille Steinmetz

E-mail: cpos@bib.bund.de
Scientific Advisory Board / Wissenschaftlicher Beirat Jürgen Dorbritz (Wiesbaden) Paul Gans (Mannheim)

Johannes Huinink (Bremen)

Marc Luy (Wien)

Clara H. Mulder (Groningen)

Notburga Ott (Bochum)

Peter Preisendörfer (Mainz)

\section{Board of Reviewers / Gutachterbeirat}

Martin Abraham (Erlangen)

Laura Bernardi (Lausanne)

Hansjörg Bucher (Bonn)

Claudia Diehl (Göttingen)

Andreas Diekmann (Zürich)

Gabriele Doblhammer-Reiter (Rostock)

Henriette Engelhardt-Wölfler (Bamberg)

E.-Jürgen Flöthmann (Bielefeld)

Alexia Fürnkranz-Prskawetz (Wien)

Beat Fux (Zürich)

Joshua Goldstein (Rostock)

Karsten Hank (Köln)

Sonja Haug (Regensburg)

Franz-Josef Kemper (Berlin) †

Michaela Kreyenfeld (Rostock)

Aart C. Liefbroer (Den Haag)

Kurt Lüscher (Konstanz)

Dimiter Philipov (Wien)

Tomáš Sobotka (Wien)

Heike Trappe (Rostock) 